The Astrophysical JouRnal, 501:207-220, 1998 July 1

(C) 1998. The American Astronomical Society. All rights reserved. Printed in U.S.A.

\title{
THE SENSITIVITY OF GAS-PHASE CHEMICAL MODELS OF INTERSTELLAR CLOUDS TO C AND O ELEMENTAL ABUNDANCES AND TO A NEW FORMATION MECHANISM FOR AMMONIA
}

\author{
R. TERZIEVA \\ Department of Chemistry and Chemical Physics Program, The Ohio State University, Columbus, OH 43210-1106 \\ AND \\ ERIC HERBST \\ Departments of Physics and Astronomy, The Ohio State University, Columbus, OH 43210-1106 \\ Received 1997 November 6; accepted 1998 February 9
}

\begin{abstract}
The effects of variations in the gas-phase carbon-to-oxygen elemental abundance ratio $(0.42 \leq$ $\mathrm{C} / \mathrm{O} \leq 1.2)$ and the absolute gas-phase carbon and oxygen elemental abundances on calculated molecular concentrations have been studied for three gas-phase chemical models of dense interstellar clouds. Both the $\mathrm{C}$ and $\mathrm{O}$ elemental abundances were varied from their "low metal" values, in which $\mathrm{C} /$ $\mathrm{O}=0.42$. The results were compared with observations of the dark interstellar clouds TMC-1 and L134N, the latter being chosen because TMC-1, with its singularly rich component of large hydrocarbons and cyanopolyynes, may not represent dense cores universally. In general, variations in the gasphase $\mathrm{C}$ and $\mathrm{O}$ elemental abundances have a large and time-dependent effect on calculated molecular concentrations for all three models. For the "new standard" model, which does not contain many rapid neutral-neutral reactions, excellent "early-time" agreement with TMC-1 occurs for a variety of C/O ratios obtained by depleting the low metal $\mathrm{O}$ abundance, but the time of best agreement tends to increase with increasing $\mathrm{C} / \mathrm{O}$ ratio. At these early times, $\approx 80 \%$ of the calculated abundances are within an order of magnitude of the observed values. Agreement at this level also occurs at steady state if the C and $\mathrm{O}$ abundances are first depleted by a factor of 5 and then $\mathrm{O}$ is additionally depleted so that $\mathrm{C} /$ $\mathrm{O} \geq 0.80$. In general, a factor of 5 depletion of both $\mathrm{C}$ and $\mathrm{O}$ increases the production efficiency of large molecules. When the new standard model is applied to L134N, the early-time agreement is not as good as for TMC-1 unless both $\mathrm{C}$ and $\mathrm{O}$ are first depleted by factors of 5 from their low metal values and the $\mathrm{C} / \mathrm{O}$ ratio is then maintained at a value less than 0.80 . Under these conditions, the steady state results are only slightly worse. The other two models, containing fast neutral-neutral reactions, have their best agreement with TMC-1 when $\mathrm{C} / \mathrm{O} \geq 1$, although the level of agreement is typically worse than with the new standard model, and factor of 5 depletions have little effect. For L134N, on the other hand, the early-time agreement with these latter two models for a wide range of $\mathrm{C} / \mathrm{O}$ values is almost as good as with the new standard model if factor of 5 depletions in $\mathrm{C}$ and $\mathrm{O}$ are utilized and is actually superior for most cases when $\mathrm{C} / \mathrm{O} \geq 1$. In general, the negative conclusions concerning models with rapid neutralneutral reactions may therefore be overly harsh. When the newly studied rapid reaction $\mathrm{H}_{3}^{+}+\mathrm{N} \rightarrow \mathrm{NH}_{2}^{+}$ $+\mathrm{H}$ is included in our model calculations, the abundances of some $\mathrm{N}$-containing species are in better agreement with observed values, but this effect decreases as $\mathrm{C} / \mathrm{O}$ is increased.
\end{abstract}

Subject headings: ISM: abundances - ISM: clouds - ISM: molecules - molecular processes

\section{INTRODUCTION}

The extent of elemental carbon and oxygen residing in the gas phase of interstellar clouds has been and still is of significant interest and importance. Early measurements by Morton (1975) on diffuse clouds showed the elements C, N, and $\mathrm{O}$ to be depleted by factors of 2.5-6 from solar values, although more recent measurements on these sources (e.g., Grevesse, Noels, \& Saural 1996; Meyer 1997) indicate more modest depletions. In dense clouds, the extent of elemental depletion onto dust grains is still very uncertain observationally. The most popular elemental abundances used in gas-phase models are now known as low metal abundances (Graedel, Langer, \& Frerking 1982; Leung, Herbst, \& Huebner 1984; Lee, Bettens, \& Herbst 1996); in these, the elements $\mathrm{C}, \mathrm{N}$, and $\mathrm{O}$ are depleted according to Morton (1975), while the elements $\mathrm{S}, \mathrm{Si}, \mathrm{Na}, \mathrm{Mg}, \mathrm{Fe}, \mathrm{P}$, and $\mathrm{Cl}$ are far more heavily depleted (Millar, Farquhar, \& Willacy 1997). Such abundances lead to better agreement with observed molecular concentrations than the so-called high metal abundances, in which the depletions of the heavier elements are more minor. The best agreement for dense clouds has generally been perceived to occur at so-called early times, which occur between $10^{5}$ and $10^{6} \mathrm{yr}$ after the onset of the chemistry, rather than at steady state, which is reached at times of $10^{7}-10^{8} \mathrm{yr}$. Indeed, in the absence of an efficient desorption mechanism for molecules adsorbed on interstellar grains, it is difficult to see how gas-phase molecules can remain in the gas long enough for steady state conditions to be reached. Even at early times, one expects some depletion of gas-phase material onto the grains in cold dense clouds (Hasegawa, Herbst, \& Leung 1992).

Rather modest depletions of elemental $\mathrm{C}$ and $\mathrm{O}$ from the gas in dense clouds have been derived by Shalabiea \& Greenberg (1995) to account for condensed phase CO and water, while more severe depletions of $\approx 3-5$ with respect to their low metal values have been proposed recently by Caselli et al. (1998) to boost the predicted abundances of complex molecules such as $\mathrm{HC}_{3} \mathrm{~N}$ in steady state model calculations of dense cloud cores. In agreement with Caselli et al. (1998), Ruffle et al. (1997) have shown in their models 
that the time-dependent depletion of gaseous material onto grains enhances the late-time abundance of $\mathrm{HC}_{3} \mathrm{~N}$. In contrast with these examinations of depletions from the gas, higher abundances of the element sulfur than used in low metal values are associated with the phenomenon of bistability, in which the differential equations used to model the gas-phase chemistry lead to two stable solutions rather than to one (Lee et al. 1998). Bistability disappears, however, when high metal abundances are used in model calculations.

In addition to studies concerning the effect on molecular abundances of general depletions of $\mathrm{C}$, $\mathrm{O}$, and other elements from the gas phase, the effect on dense cloud molecular abundances of variations in the $\mathrm{C} / \mathrm{O}$ elemental abundance ratio has been investigated, typically by changing one of the elements from its low metal value. Recently, Bergin et al. (1997) showed that an increase in the $\mathrm{C} / \mathrm{O}$ elemental abundance ratio from 0.4 (approximately the low metal value) to 0.8 enhances the agreement between their early-time calculated abundances and observed values in some giant cloud cores. In addition, Pratap et al. (1997), in their very detailed study of abundance gradients in TMC-1, found that one method of reproducing the observed gradients is to vary the $\mathrm{C} / \mathrm{O}$ ratio from 0.4 to 0.5 at early time, which is a rather small change. Previously, Bettens, Lee, \& Herbst (1995) had showed that with a C/O abundance ratio greater than unity, large non-oxygen-containing molecules could be produced efficiently even in models for which no large molecules can be synthesized efficiently if $\mathrm{C} / \mathrm{O}=0.42$. Despite all of the studies mentioned here, we are not aware of a general study on the effect of changes in the $\mathrm{C}$ and $\mathrm{O}$ elemental abundances, both equal and unequal, on calculated molecular abundances in time-dependent gas-phase models. Such a study might help to constrain the extent of depletions of $\mathrm{C}$ and $\mathrm{O}$ in dense clouds, since this extent is clearly poorly determined. Possible excess depletion of $\mathrm{O}$ onto grains, compared with $\mathrm{C}$, can be caused by chemical conversion of adsorbed $\mathrm{O}$ into ice, which essentially remains on the surface; while methane, the saturated form of $\mathrm{C}$, is more likely to return to the gas (Bergin et al. 1997).

In this paper, we examine the effect of such changes on calculated molecular abundances in three of our large model networks - the new standard model, the new neutralneutral model, and model 4 (Bettens et al. 1995). The first model does not contain rapid neutral-neutral reactions to the extent of the latter two. We are concerned with two types of depletions: first, relatively small changes in either the carbon or the oxygen elemental abundance resulting in a change in the $\mathrm{C} / \mathrm{O}$ ratio from the low metal value of 0.42 through 1.2 and, secondly, a relatively large but equal depletion of a factor of 5 in the $\mathrm{C}$ and $\mathrm{O}$ elemental abundances, followed by the same variation in $\mathrm{C} / \mathrm{O}$ without the general depletion. Our research has not been focused on the performance of the models for individual species, but rather on the overall agreement for all species detected in two rather distinct and well-studied dark interstellar clouds: TMC-1 and L134N. Detailed results as a function of time and density are given by Lee et al. (1996) for low and high metal abundances at two temperatures. Initially we evaluated our results by comparison with the many molecular abundances measured in TMC-1 because this cloud was considered to be a "typical" dark cloud. However, it is becoming reasonably clear that TMC-1, especially TMC-1 (cyanopolyyne peak), is unique among dense cloud cores in its high abundances of complex molecules (see, e.g., Caselli et al. 1998; Pratap et al. 1997). In addition to TMC-1, we therefore chose another well-studied dark cloud-L134Nfor comparison.

Our approach prevents us from being biased while choosing the species of interest. For example, our calculations show cases of significant underproduction of methanol and acetaldehyde, which we might not notice if we were choosing only non-oxygen-containing species for study. A possible problem with our approach is the blending of results for many species so as to lose detailed information on the behavior of certain classes of molecules, which we try to avoid by separating the species into groups.

While our study was progressing, we learned of a new experimental measurement (Scott et al. 1997a) on the reaction

$$
\mathrm{H}_{3}^{+}+\mathrm{N} \rightarrow \mathrm{NH}_{2}^{+}+\mathrm{H},
$$

which showed the reaction to be rapid at room temperature, as opposed to previous theoretical studies (Herbst, DeFrees, \& McLean 1987), which indicated a negligible rate. We have neglected any possible temperature dependence and have incorporated this rapid reaction $\left(k=4.5 \times 10^{-10} \mathrm{~cm}^{3}\right.$ $s^{-1}$ ) into our model networks so that we can report on its significance. We expect this reaction to improve the efficiency of the production of ammonia, since the product ion is converted into $\mathrm{NH}_{4}^{+}$by successive reactions with molecular hydrogen and $\mathrm{NH}_{4}^{+}$is assumed to react dissociatively with electrons to produce ammonia. A preliminary assessment of the effect of reaction (1) has already been made (Scott, Freeman, \& McEwan 1997b).

In the next section, we describe the reaction networks and the sets of elemental abundance used for our calculations. This is followed by the results we obtained and their interpretation.

\section{MODELS}

The models used are actually modifications of the new standard model (hereafter NSM), the new neutral-neutral model (hereafter NNNM), and model 4 (hereafter M4), as described by Bettens et al. (1995). In the models, the rate coefficient for the reaction between $\mathrm{HOC}^{+}$and $\mathrm{H}_{2}$ has been updated according to Herbst \& Woon (1996), while a new temperature-dependent rate coefficient for the neutralneutral reaction of $\mathrm{O}$ and $\mathrm{OH}$ has been adopted (Smith \& Stewart 1994). In addition, the product branching fractions for the dissociative recombination reactions involving $\mathrm{H}_{2} \mathrm{O}^{+}, \mathrm{H}_{3} \mathrm{O}^{+}, \mathrm{CH}_{3}^{+}$, and electrons have been changed according to the storage ring experimental results performed by Vejby-Christensen et al. (1997). An analogous storage ring experiment for $\mathrm{H}_{3}^{+}$with electrons gives a product ratio of $73 \%$ for the $3 \mathrm{H}$ channel and $27 \%$ for the $\mathrm{H}_{2}+\mathrm{H}$ channel (Larsson et al. 1996) with an overall rate coefficient of $1.12 \times 10^{-7}(T / 300)^{-0.65} \mathrm{~cm}^{3} \mathrm{~s}^{-1}$ (M. Larsson 1997, private communication); these values have been used in the models.

A major modification has been made to model M4. This model is distinguished from the NNNM by the removal of reactions of the sort

$$
\begin{gathered}
\mathrm{O}+\mathrm{C}_{n} \rightarrow \mathrm{CO}+C_{n-1}, \\
\mathrm{~N}+\mathrm{C}_{n} \rightarrow \mathrm{CN}+C_{n-1}
\end{gathered}
$$

between carbon clusters with $n>2$ and reactive atoms. The only evidence, pro or con, concerning the rates of these 
reactions has been obtained theoretically by Woon \& Herbst (1996), who calculated the rate for the reaction between $\mathrm{O}$ and $\mathrm{C}_{3}$ at low temperatures to be slow because of an activation energy barrier. The ground electronic states of the linear carbon clusters with an even number of carbon atoms have triplet multiplicity, however, and are, in general, expected to be more reactive than the carbon clusters with an odd number of carbon atoms, which possess singlet ground states. We have therefore set the rate coefficients for the above reactions back to the NNNM values of $k=1.0 \times 10^{-10} \mathrm{~cm}^{3} \mathrm{~s}^{-1}$ for $n=4,6$, and 8 . The modified M4 model, hereafter referred to as M4M, is expected to be less efficient in the production of complex molecules than M4 because, in general, neutral-neutral reactions of types (2) and (3) hinder molecular synthesis.

The temperature used in all model calculations is $T=10$ $\mathrm{K}$, as suggested by the most recent temperature determinations in TMC-1 (Pratap et al. 1997) and by the compilation of dense core data by Caselli et al. (1998). The total hydrogen density has been assumed to be $n_{\mathrm{H}}=2 n\left(\mathrm{H}_{2}\right)$ $+n(\mathrm{H})=2 \times 10^{4} \mathrm{~cm}^{-3}$, and the visual extinction has been assumed to be large enough that external photons play no role in the chemistry. Except for the $\mathrm{C}$ and $\mathrm{O}$ elemental abundances, low metal abundances have been used (Lee et al. 1997). The initial form for hydrogen is the neutral molecule $\mathrm{H}_{2}$; the initial form for oxygen, nitrogen and helium is the neutral atom; and for all other elements the initial form is the singly ionized atom. A standard cosmic-ray ionization rate $\zeta$ of $1.3 \times 10^{-17} \mathrm{~s}^{-1}$ for $\mathrm{H}_{2}$ has been utilized. Under these conditions, no bistability was observed. Higher cosmic-ray ionization rates and gas densities have been inferred by Pratap et al. (1997) for TMC-1 and by Caselli et al. (1998) for a variety of dense cloud cores. In the work of Pratap et al. (1997), a density about a factor of 4 higher is used for TMC-1 at the cyanopolyyne peak. At steady state, it can be shown that density and cosmic-ray ionization rate scale such that the calculated abundances are a function only of their ratio. The effect of the higher ionization rates is thus canceled by higher gas densities (Lee et al. 1998).

In order to study the effects of changes in the $\mathrm{C}$ and $\mathrm{O}$ elemental abundances, we have used the sets of elemental abundances shown in Table 1 . In this table, set 1 represents the standard low metal (or high metal) values for $\mathrm{C}$ and $\mathrm{O}$. Sets 2-5 represent successive depletions of $\mathrm{O}$ such that $\mathrm{C} / \mathrm{O}$ reaches a high value of 1.2 by set 5 . Sets 6-9 represent

TABLE 1

Carbon and Oxygen Elemental Abundances WITH RESPECT TO H

\begin{tabular}{|c|c|c|c|}
\hline Set & Oxygen & Carbon & $\mathrm{C} / \mathrm{O}$ \\
\hline $1 \ldots$ & $1.76 \mathrm{E}-4^{\mathrm{a}}$ & $7.30 \mathrm{E}-5^{\mathrm{a}}$ & $0.42^{\mathrm{a}}$ \\
\hline $2 \ldots$ & $1.22 \mathrm{E}-4$ & $7.30 \mathrm{E}-5$ & 0.60 \\
\hline$\ldots \ldots$ & $9.13 E-5$ & $7.30 \mathrm{E}-5$ & 0.80 \\
\hline $4 \ldots$ & $7.30 \mathrm{E}-5$ & $7.30 \mathrm{E}-5$ & 1.0 \\
\hline $5 \ldots \ldots \ldots \ldots$ & $6.08 \mathrm{E}-5$ & $7.30 \mathrm{E}-5$ & 1.2 \\
\hline $6 \ldots \ldots \ldots \ldots$ & $1.76 \mathrm{E}-4$ & $1.06 \mathrm{E}-4$ & 0.60 \\
\hline $7 \ldots \ldots$ & $1.76 \mathrm{E}-4$ & $1.41 \mathrm{E}-4$ & 0.80 \\
\hline 8 & $1.76 \mathrm{E}-4$ & $1.76 \mathrm{E}-4$ & 1.0 \\
\hline$\ldots$ & $1.76 \mathrm{E}-4$ & $2.11 \mathrm{E}-4$ & 1.2 \\
\hline $10 \ldots \ldots$ & $3.52 \mathrm{E}-5$ & $1.46 \mathrm{E}-5$ & 0.42 \\
\hline $11 \ldots \ldots \ldots \ldots$ & $2.43 E-5$ & $1.46 \mathrm{E}-5$ & 0.60 \\
\hline $12 \ldots \ldots \ldots \ldots$ & $1.83 E-5$ & $1.46 \mathrm{E}-5$ & 0.80 \\
\hline $13 \ldots \ldots \ldots \ldots$ & $1.46 \mathrm{E}-5$ & $1.46 \mathrm{E}-5$ & 1.0 \\
\hline $14 \ldots \ldots \ldots \ldots$ & $1.22 \mathrm{E}-5$ & $1.46 \mathrm{E}-5$ & 1.2 \\
\hline
\end{tabular}

${ }^{\text {a }}$ Low and high metal value. successive increases of $\mathrm{C}$ from set 1 until the $\mathrm{C} / \mathrm{O}$ ratio again reaches 1.2. In set 10 , the low metal $\mathrm{C}$ and $\mathrm{O}$ elemental abundances are each depleted by a factor of 5 so that the $\mathrm{C} / \mathrm{O}$ ratio remains at 0.42 ; additional depletions of $\mathrm{O}$ are represented by sets $11-14$ as the $\mathrm{C} / \mathrm{O}$ ratio is raised to 1.2 . In general, the results using sets 6-9 are worse than those using sets $2-5$, and we do not report the former results in any detail.

The depletions from standard elemental abundances used here should not be confused with dynamic depletions that occur in gas-grain models. In these latter models (see, e.g., Ruffle et al. 1997), depletion of material from the gas occurs continuously, and, in the absence of an efficient desorption mechanism, the gas phase will eventually be totally depleted of heavy species, although the depletion of some gas-phase species can temporarily enhance the abundances of others.

\section{RESULTS}

To compare our calculated abundances with observed abundances in TMC-1 and in L134N, we used the parameter $N_{\text {agree }} / N_{\text {total }}$, where $N_{\text {agree }}$ is the number of species with calculated abundances within 1 order of magnitude of the observed abundances and $N_{\text {total }}$ is the total number of species detected in the cloud (Bettens et al. 1995). This global approach is complementary to the detailed approach of Pratap et al. (1997), in which detailed abundances and abundance gradients for 13 molecules in TMC-1 were studied observationally and theoretically. We sometimes refer to the parameter $N_{\text {agree }} / N_{\text {total }}$ as the molecular production efficiency. A list of the observed species in TMC-1 and L134N with their abundances (with respect to $\mathrm{H}_{2}$ ) that we used in our comparison is given in Table 2. The TMC-1 abundances are peak values. Detailed abundances and abundance variations with respect to $\mathrm{HCO}^{+}$have been provided by Pratap et al. (1997) for 13 species, but their degree of detail exceeds the purpose of our study here. To help elucidate some of our results, the species in each cloud were divided into four groups using the following rules. First, all the species containing sulfur atoms constitute the $S$ group. Secondly, of the remaining species, those containing nitrogen atoms constitute the $\mathrm{N}$ group. Thirdly, of the species still remaining, those containing oxygen atoms form the $\mathrm{O}$ group. Finally, the remainder, which consist of carbon clusters and hydrocarbons, constitute the $\mathrm{C}$ group. For example, $\mathrm{SO}_{2}$ and $\mathrm{OCS}$ belong to the $\mathrm{S}$ group, while $\mathrm{H}_{2} \mathrm{CO}$ is in the $\mathrm{O}$ group. The molecules in TMC-1 and L134N in each group are listed in Table 3.

Before discussing the effect of varying the $\mathrm{C}$ and $\mathrm{O}$ elemental abundances, let us consider the effect of reaction (1). In Table 4 we list the ratios at selected times of calculated abundances for molecules obtained with the addition of the new reaction to those obtained without this rapid reaction. Table 4 includes only those species that change in abundance by an order of magnitude or more at at least one time. In the calculation, the NSM was used with the standard low metal set of elemental abundances. It can be seen that the included molecules, which all contain nitrogen, all increase in abundance. The largest effect occurs at a time of $1 \times 10^{6} \mathrm{yr}$, when some concentrations, such as that of ammonia, rise by 2 orders of magnitude or more. A comparison between the results for different $\mathrm{C} / \mathrm{O}$ ratios shows that with increasing $\mathrm{C} / \mathrm{O}$, the effects of reaction (1) decrease.

Although the inclusion of reaction (1) enhances the abundances of nitrogen-containing molecules, especially for low 
TABLE 2

Fractional AbUNDANCES ${ }^{\text {a }}$ OF SPECIES ObSERVED IN TMC-1 AND L134N WITH RESPECT TO $\mathrm{H}_{2}$

\begin{tabular}{|c|c|c|c|c|c|}
\hline Species & TMC-1 & L134N & Species & TMC-1 & L134N \\
\hline $\mathrm{C}_{2}$. & $5 \mathrm{E}-8$ & & $\mathrm{CH}$. & $2 \mathrm{E}-8$ & $1 \mathrm{E}-8$ \\
\hline & $3 E-8$ & $3 E-9$ & $\mathrm{CO}$ & $8 \mathrm{E}-5$ & $8 \mathrm{E}-5$ \\
\hline $\mathrm{CS}$. & $1 \mathrm{E}-8$ & $1 \mathrm{E}-9$ & NO . & $3 \mathrm{E}-8$ & $6 \mathrm{E}-8$ \\
\hline $\mathrm{OH}$. & $3 \mathrm{E}-7$ & $8 \mathrm{E}-8$ & SO.. & $5 \mathrm{E}-9$ & $2 \mathrm{E}-8$ \\
\hline $\mathrm{C}_{2} \mathrm{H}$. & $5 E-8$ & $5 E-8$ & $\mathrm{C}_{2} \mathrm{~S}$. & $8 \mathrm{E}-9$ & $6 \mathrm{E}-10$ \\
\hline $\mathrm{C}_{2} \mathrm{O} \ldots$ & $6 \mathrm{E}-10$ & & $\mathrm{H}_{2} \mathrm{~S}$. & $5 E-10$ & $8 \mathrm{E}-10$ \\
\hline $\mathrm{HCN}$. & $2 \mathrm{E}-8$ & $4 E-9$ & HNC. & $2 \mathrm{E}-8$ & $6 \mathrm{E}-9$ \\
\hline OCS.. & $2 \mathrm{E}-9$ & $2 E-9$ & $\mathrm{SO}_{2}$ & $1 E-9$ & $4 \mathrm{E}-9$ \\
\hline $\mathrm{C}_{3} \mathrm{H} \ldots$ & $5 \mathrm{E}-10$ & $3 E-10$ & $\mathrm{C}_{3} \mathrm{~N} .$. & $1 \mathrm{E}-9$ & $2 E-10$ \\
\hline $\mathrm{C}_{3} \mathrm{O} \ldots \ldots \ldots$ & $1 \mathrm{E}-10$ & $5 E-11$ & $\mathrm{C}_{3} \mathrm{~S} \ldots \ldots$ & $1 E-9$ & $2 \mathrm{E}-10$ \\
\hline $\mathrm{H}_{2} \mathrm{CO} \ldots \ldots \ldots$ & $2 \mathrm{E}-8$ & $2 \mathrm{E}-8$ & $\mathrm{H}_{2} \mathrm{CS} .$. & $3 E-9$ & $6 \mathrm{E}-10$ \\
\hline $\mathrm{NH}_{3} \ldots \ldots \ldots \ldots$ & $2 E-8$ & $2 E-7$ & $\mathrm{CH}_{2} \mathrm{CN}$.. & $5 E-9$ & $1 \mathrm{E}-9$ \\
\hline $\mathrm{CH}_{2} \mathrm{CO} \ldots \ldots \ldots$ & $1 \mathrm{E}-9$ & $7 E-10$ & $\mathrm{C}_{3} \mathrm{H}_{2} \ldots \ldots \ldots \ldots$ & $3 \mathrm{E}-8$ & $2 \mathrm{E}-9$ \\
\hline $\mathrm{C}_{4} \mathrm{H} \ldots \ldots \ldots \ldots$ & $2 E-8$ & $1 \mathrm{E}-9$ & HCOOH ...... & $2 \mathrm{E}-10$ & $3 E-10$ \\
\hline $\mathrm{HC}_{3} \mathrm{~N} \ldots \ldots \ldots$ & $6 \mathrm{E}-9$ & $2 \mathrm{E}-10$ & $\mathrm{CH}_{3} \mathrm{CN} \ldots \ldots \ldots$ & $1 \mathrm{E}-9$ & $1 \mathrm{E}-9$ \\
\hline $\mathrm{C}_{4} \mathrm{H}_{2}^{b}$. & $1 \mathrm{E}-9$ & & $\mathrm{C}_{5} \mathrm{H} \ldots \ldots \ldots \ldots$ & $3 E-10$ & \\
\hline $\mathrm{CH}_{3} \mathrm{OH} \ldots$. & $2 \mathrm{E}-9$ & $3 E-9$ & $\mathrm{CH}_{3} \mathrm{CHO} \ldots \ldots$ & $6 \mathrm{E}-10$ & $6 \mathrm{E}-10$ \\
\hline $\mathrm{C}_{2} \mathrm{H}_{3} \mathrm{CN} \ldots \ldots$ & $2 \mathrm{E}-10$ & $1 \mathrm{E}-10$ & $\mathrm{C}_{3} \mathrm{H}_{4} \ldots \ldots \ldots \ldots$ & $6 \mathrm{E}-9$ & $1 \mathrm{E}-9$ \\
\hline $\mathrm{C}_{6} \mathrm{H} \ldots \ldots \ldots \ldots$ & $1 \mathrm{E}-10$ & $\ldots$ & $\mathrm{HC}_{5} \mathrm{~N} \ldots \ldots \ldots$ & $3 E-9$ & $1 \mathrm{E}-10$ \\
\hline $\mathrm{C}_{6} \mathrm{H}_{2}{ }^{\mathrm{b}} \ldots \ldots \ldots$ & $5 \mathrm{E}-11$ & $\ldots$ & $\mathrm{CH}_{3} \mathrm{C}_{3} \mathrm{~N} \ldots \ldots$. & $5 E-10$ & \\
\hline $\mathrm{CH}_{3} \mathrm{C}_{4} \mathrm{H} \ldots$ & $2 E-10$ & $\ldots$ & $\mathrm{HC}_{7} \mathrm{~N} \ldots \ldots \ldots$ & $1 \mathrm{E}-9$ & $2 \mathrm{E}-11$ \\
\hline $\mathrm{HC}_{9} \mathrm{~N} \ldots \ldots$. & $3 E-10$ & & $\mathrm{HCO}^{+} \ldots \ldots \ldots$ & $8 \mathrm{E}-9$ & $8 \mathrm{E}-9$ \\
\hline $\mathrm{HCS}^{+} \ldots \ldots$. & $6 \mathrm{E}-10$ & $6 \mathrm{E}-11$ & $\mathrm{~N}_{2} \mathrm{H}^{+} \ldots \ldots \ldots$ & $5 \mathrm{E}-10$ & $5 \mathrm{E}-10$ \\
\hline $\mathrm{HCNH}^{+}$ & $2 \mathrm{E}-9$ & $3 \mathrm{E}-9$ & $\ldots$ & $\ldots$ & $\ldots$ \\
\hline
\end{tabular}

a Ohishi, Irvine, \& Kaifu 1992 unless otherwise noted.

${ }^{\mathrm{b}}$ Langer et al. 1997.

$\mathrm{C} / \mathrm{O}$ ratios, it is not clear that this enhancement will result in better agreement between theory and observation in a global sense. The effect on the comparison between model and observation is shown in Figure 1, where the parameter $N_{\text {agree }} / N_{\text {total }}$ is plotted versus time for TMC-1 using six models run with the standard $\mathrm{C}$ and $\mathrm{O}$ abundances (set 1 ). The six models are the NSN, M4M, and NNNM, run both with and without reaction (1). One can see in this figure that the inclusion of reaction (1) never worsens the global agreement and, more so at steady state than at early time, tends to improve things considerably. For example, the parameter $N_{\text {agree }} / N_{\text {total }}$ increases at steady state for the NSM from 0.23 to 0.32 , which means that four additional molecules reach the 1 order of magnitude criterion. These molecules are $\mathrm{CN}$, $\mathrm{HCN}, \mathrm{HNC}$, and $\mathrm{C}_{3} \mathrm{H}$. The last one does not contain N, but its abundance increases slightly, which is enough to satisfy the 1 order of magnitude criterion. With the standard $\mathrm{C}$ and O elemental abundances, however, only the NSM at early time is in very good global agreement with observation $\left(N_{\text {agree }} / N_{\text {total }} \approx 0.8\right)$. In the rest of the paper, all results are based on data obtained using a rate coefficient of $4.5 \times 10^{-10} \mathrm{~cm}^{3} \mathrm{~s}^{-1}$ for reaction (1).

Our major results showing the general comparison between model and observation as a function of $\mathrm{C}$ and $\mathrm{O}$ elemental abundances are shown on a series of figures. Figures 2-5 refer to the agreement between models NSM, M4M, and NNNM, with observations in TMC-1, while Figures 6-9 refer to the agreement between these models and observations in L134N. In Figures 2-4 and Figures 6-8, the molecular production efficiency is given as a stacked

TABLE 3

SEParation of the Species INTo Groups

\begin{tabular}{|c|c|c|c|c|c|c|c|}
\hline \multicolumn{2}{|c|}{ CARBON GROUP } & \multicolumn{2}{|c|}{ OXYGEN GROUP } & \multicolumn{2}{|c|}{ NITROGEN GROUP } & \multicolumn{2}{|c|}{ SULPHUR GROUP } \\
\hline TMC-1 & L134N & TMC-1 & L134N & TMC-1 & L134N & TMC-1 & L134N \\
\hline $\begin{array}{l}\mathrm{C}_{2} \\
\mathrm{CH} \\
\mathrm{C}_{2} \mathrm{H} \\
\mathrm{C}_{3} \mathrm{H} \\
\mathrm{C}_{3} \mathrm{H}_{2} \\
\mathrm{C}_{4} \mathrm{H} \\
\mathrm{C}_{4} \mathrm{H}_{2} \\
\mathrm{C}_{5} \mathrm{H} \\
\mathrm{C}_{3} \mathrm{H}_{4} \\
\mathrm{C}_{6} \mathrm{H} \\
\mathrm{C}_{6} \mathrm{H}_{2} \\
\mathrm{CH}_{3} \mathrm{C}_{4} \mathrm{H}\end{array}$ & $\begin{array}{l}\mathrm{CH} \\
\mathrm{C}_{2} \mathrm{H} \\
\mathrm{C}_{3} \mathrm{H} \\
\mathrm{C}_{3} \mathrm{H}_{2} \\
\mathrm{C}_{4} \mathrm{H} \\
\mathrm{C}_{3} \mathrm{H}_{4}\end{array}$ & $\begin{array}{l}\mathrm{CO} \\
\mathrm{OH} \\
\mathrm{C}_{2} \mathrm{O} \\
\mathrm{C}_{3} \mathrm{O} \\
\mathrm{H}_{2} \mathrm{CO} \\
\mathrm{CH}_{2} \mathrm{CO} \\
\mathrm{HCOOH} \\
\mathrm{CH}_{3} \mathrm{OH} \\
\mathrm{CH}_{3} \mathrm{CHO} \\
\mathrm{HCO}^{+}\end{array}$ & $\begin{array}{l}\mathrm{CO} \\
\mathrm{OH} \\
\mathrm{C}_{3} \mathrm{O} \\
\mathrm{H}_{2} \mathrm{CO} \\
\mathrm{CH}_{2} \mathrm{CO} \\
\mathrm{HCOOH} \\
\mathrm{CH}_{3} \mathrm{OH} \\
\mathrm{CH}_{3} \mathrm{CHO} \\
\mathrm{HCO}^{+}\end{array}$ & $\begin{array}{l}\mathrm{CN} \\
\mathrm{NO} \\
\mathrm{HCN} \\
\mathrm{HNC} \\
\mathrm{C}_{3} \mathrm{~N} \\
\mathrm{NH}_{3} \\
\mathrm{CH}_{2} \mathrm{CN} \\
\mathrm{HC}_{3} \mathrm{~N} \\
\mathrm{CH}_{3} \mathrm{CN} \\
\mathrm{C}_{2} \mathrm{H}_{3} \mathrm{CN} \\
\mathrm{HC}_{5} \mathrm{~N} \\
\mathrm{CH}_{3} \mathrm{C}_{3} \mathrm{~N} \\
\mathrm{HC}_{7} \mathrm{~N} \\
\mathrm{HC}_{9} \mathrm{~N} \\
\mathrm{~N}_{2} \mathrm{H}^{+} \\
\mathrm{HCNH}^{+}\end{array}$ & $\begin{array}{l}\mathrm{CN} \\
\mathrm{NO} \\
\mathrm{HCN} \\
\mathrm{HNC} \\
\mathrm{C}_{3} \mathrm{~N} \\
\mathrm{NH}_{3} \\
\mathrm{CH}_{2} \mathrm{CN} \\
\mathrm{HC}{ }_{3} \mathrm{~N} \\
\mathrm{CH}_{3} \mathrm{CN} \\
\mathrm{C}_{2} \mathrm{H}_{3} \mathrm{CN} \\
\mathrm{HC}_{5} \mathrm{~N} \\
\mathrm{HC}_{7} \mathrm{~N} \\
\mathrm{~N}_{2} \mathrm{H}^{+} \\
\mathrm{HCNH}^{+}\end{array}$ & $\begin{array}{l}\mathrm{CS} \\
\mathrm{SO} \\
\mathrm{C}_{2} \mathrm{~S} \\
\mathrm{H}_{2} \mathrm{~S} \\
\mathrm{OCS} \\
\mathrm{SO}_{2} \\
\mathrm{C}_{3} \mathrm{~S} \\
\mathrm{H}_{2} \mathrm{CS} \\
\mathrm{HCS}^{+}\end{array}$ & $\begin{array}{l}\mathrm{CS} \\
\mathrm{SO} \\
\mathrm{C}_{2} \mathrm{~S} \\
\mathrm{H}_{2} \mathrm{~S} \\
\mathrm{OCS} \\
\mathrm{SO}_{2} \\
\mathrm{C}_{3} \mathrm{~S} \\
\mathrm{H}_{2} \mathrm{CS} \\
\mathrm{HCS}^{+}\end{array}$ \\
\hline
\end{tabular}


TABLE 4

Ratios of Calculated Abundances When Reaction (1) Is INCLUDED to WhEN It Is OMITTED

\begin{tabular}{|c|c|c|c|}
\hline Species & $1.0 \mathrm{E} 5 \mathrm{yr}$ & $1.0 \mathrm{E} 6 \mathrm{yr}$ & $1.0 \mathrm{E} 8 \mathrm{yr}$ \\
\hline NH . & $5.18 \mathrm{E} 0$ & $7.36 \mathrm{E} 1$ & 7.17E0 \\
\hline HNO.. & $1.40 \mathrm{E} 1$ & $1.21 \mathrm{E} 2$ & $7.01 \mathrm{E} 0$ \\
\hline $\mathrm{N}_{2} \mathrm{O} \ldots \ldots$ & $1.17 \mathrm{E} 1$ & $5.71 \mathrm{E} 1$ & $3.08 \mathrm{E} 0$ \\
\hline $\mathrm{NO}_{2} \ldots \ldots$ & $1.41 \mathrm{E} 1$ & $1.31 \mathrm{E} 2$ & $9.30 \mathrm{E} 0$ \\
\hline $\mathrm{NH}_{3} \ldots \ldots \ldots$ & $1.34 \mathrm{E} 1$ & $1.25 \mathrm{E} 2$ & $7.29 \mathrm{E} 0$ \\
\hline $\mathrm{NH}_{2} \mathrm{CN} \ldots \ldots$ & $1.47 \mathrm{E} 1$ & $5.23 \mathrm{E} 2$ & $1.66 \mathrm{E} 1$ \\
\hline $\mathrm{CH}_{5} \mathrm{~N} \ldots \ldots$. & $1.22 \mathrm{E} 1$ & $1.37 \mathrm{E} 2$ & $7.36 \mathrm{E} 0$ \\
\hline $\mathrm{NH}_{2}^{+}$. & $1.46 \mathrm{E} 1$ & $1.12 \mathrm{E} 2$ & $6.94 \mathrm{E} 0$ \\
\hline $\mathrm{C}_{2} \mathrm{~N}_{2}^{+} \ldots \ldots \ldots \ldots$ & $1.33 \mathrm{E} 0$ & $4.28 \mathrm{E} 1$ & $6.79 \mathrm{E} 0$ \\
\hline $\mathrm{H}_{2} \mathrm{NO}^{+} \ldots \ldots \ldots \ldots$ & $1.35 \mathrm{E} 1$ & $1.29 \mathrm{E} 2$ & 7.03E0 \\
\hline $\mathrm{NH}_{3}^{+} \ldots$. & $1.45 \mathrm{E} 1$ & $1.08 \mathrm{E} 2$ & $6.81 \mathrm{E} 0$ \\
\hline $\mathrm{SiNCH}^{+}$ & $6.48 \mathrm{E} 0$ & $2.41 \mathrm{E} 1$ & $5.28 \mathrm{E} 0$ \\
\hline $\mathrm{NH}_{4}^{+} \ldots .$. & $1.43 \mathrm{E} 1$ & $1.21 \mathrm{E} 2$ & $6.96 \mathrm{E} 0$ \\
\hline $\mathrm{CH}_{4} \mathrm{~N}^{+} \ldots$ & $1.25 \mathrm{E} 1$ & $1.32 \mathrm{E} 2$ & $7.15 \mathrm{E} 0$ \\
\hline $\mathrm{CH}_{5} \mathrm{~N}^{+}$ & $1.14 \mathrm{E} 1$ & $1.19 \mathrm{E} 2$ & $6.83 \mathrm{E} 0$ \\
\hline $\mathrm{CH}_{6} \mathrm{~N}^{+}$ & $1.25 \mathrm{E} 1$ & $1.32 \mathrm{E} 2$ & $7.15 \mathrm{E} 0$ \\
\hline HNC $\ldots \ldots \ldots \ldots$ & $1.24 \mathrm{E} 0$ & $1.02 \mathrm{E} 1$ & $3.51 \mathrm{E} 0$ \\
\hline HNSi $\ldots \ldots \ldots \ldots$ & $4.85 \mathrm{E} 0$ & 2.24E1 & $4.98 \mathrm{E} 0$ \\
\hline $\mathrm{NH}_{2}, \ldots \ldots \ldots \ldots$ & $1.42 \mathrm{E} 1$ & $1.21 \mathrm{E} 2$ & 7.07E0 \\
\hline $\operatorname{SiNC} \ldots \ldots \ldots \ldots$ & $6.43 \mathrm{E} 0$ & 2.33E1 & $5.34 \mathrm{E} 0$ \\
\hline $\mathrm{CH}_{3} \mathrm{~N} \ldots \ldots \ldots \ldots$ & $1.24 \mathrm{E} 1$ & $1.35 \mathrm{E} 2$ & $7.36 \mathrm{E} 0$ \\
\hline $\mathrm{C}_{3} \mathrm{H}_{3} \mathrm{~N} \ldots \ldots \ldots \ldots$ & $1.27 \mathrm{E} 0$ & $1.23 \mathrm{E} 1$ & $4.78 \mathrm{E} 0$ \\
\hline $\mathrm{HNC}^{+} \ldots \ldots \ldots \ldots$ & $1.36 \mathrm{E} 1$ & $4.10 \mathrm{E} 2$ & $1.53 \mathrm{E} 1$ \\
\hline $\mathrm{NO}_{2}^{+} \ldots \ldots \ldots \ldots$ & $6.93 \mathrm{E} 0$ & $1.62 \mathrm{E} 1$ & $6.54 \mathrm{E} 0$ \\
\hline $\mathrm{H}_{2} \mathrm{NC}^{+} \ldots \ldots \ldots \ldots$ & $1.41 \mathrm{E} 0$ & $4.15 \mathrm{E} 1$ & $5.91 \mathrm{E} 0$ \\
\hline $\mathrm{HNCO}^{+} \ldots \ldots \ldots$ & $1.24 \mathrm{E} 0$ & $1.10 \mathrm{E} 1$ & $3.55 \mathrm{E} 0$ \\
\hline $\mathrm{PNH}_{2}^{+} \ldots \ldots \ldots \ldots$ & $1.25 \mathrm{E} 1$ & $1.04 \mathrm{E} 2$ & $6.62 \mathrm{E} 0$ \\
\hline $\mathrm{SiNH}_{2}^{+} \ldots \ldots \ldots \ldots$ & $6.55 \mathrm{E} 0$ & $2.22 \mathrm{E} 1$ & 4.83E0 \\
\hline $\mathrm{PNH}_{3}^{+} \ldots \ldots \ldots \ldots$ & $1.26 \mathrm{E} 1$ & $1.37 \mathrm{E} 2$ & $7.36 \mathrm{E} 0$ \\
\hline $\mathrm{NH}_{2} \mathrm{CNH}^{+} \ldots \ldots$ & $1.41 \mathrm{E} 1$ & $5.58 \mathrm{E} 2$ & $1.64 \mathrm{E} 1$ \\
\hline $\mathrm{C}_{3} \mathrm{H}_{4} \mathrm{~N}^{+} \ldots \ldots \ldots$ & $1.21 \mathrm{E} 0$ & $1.30 \mathrm{E} 1$ & 4.72E0 \\
\hline
\end{tabular}

NoTE-The ratios are given only for species with abundance changes of more than 1 order of magnitude at some time. The $\mathrm{C}$ and $\mathrm{O}$ elemental abundances used for the calculation are the standard ones; see set 1 in Table 1.

column versus the $\mathrm{C} / \mathrm{O}$ ratio. Each column, in turn, consists of an accumulation of four shares, given in different shades of gray, and each share gives the partial molecular production efficiency due to one of the four groups of molecules defined above. A legend on the right part of the graph shows the exact correspondence between the groups and the colors used. The maximum possible value for the production efficiency is 1 , which denotes $100 \%$ agreement with the observations, using the order-of-magnitude criterion. The maximum contribution of each group of molecules detected in a cloud can be viewed in the reference bar, which is the last column to the right. Additionally, the data on each figure are separated into sections by vertical lines. The general depletion, if any, from the standard abundances used in the calculation is given in the upper part of each section by either the number 1 (no general depletion) or the number 5 (factor of 5 depletion for both $\mathrm{C}$ and $\mathrm{O}$ ). Put in another manner, the columns represented by an equal depletion of 1 are obtained using sets 1-5 in Table 1 , while those represented by an equal depletion of 5 are obtained using sets 10-14 in Table 1. The first two sections to the left of each of the Figures 2-4 and Figures 6-8 give the results at a best early (pre-steady state) time, while the next two are for steady state, as indicated at the top of the sections. If there is no best solution time significantly before steady state, i.e., the best solution lies at or very near steady state, then the relevant column under "best early time" is left blank. The exact values for the best early times are listed in the figure captions.
In order to study the synthesis of complex molecules as a separate issue independently from the group separation in Table 3, we have defined a so-called complex group of molecules for each cloud, which includes all of the species containing four or more atoms ( 28 in the case of TMC- 1 and 21 in the case of $\mathrm{L} 134 \mathrm{~N}$ ). We realize that this is not the only criterion for complexity because some fairly simple hydrogenated species (e.g., $\mathrm{H}_{2} \mathrm{CO}, \mathrm{NH}_{3}$ ) end up being classified in this group. Also, the two complex groups are not the same because of the difference in the species observed in the two clouds. Some results for the complex group of species detected in TMC-1 are represented in Figure 5, while Figure 9 contains results for the complex group in L134N. In these figures, the best agreement for complex species is shown for all three models, for two equal $\mathrm{C}$ and $\mathrm{O}$ depletion factors of 1 and 5 , and for five different $\mathrm{C} / \mathrm{O}$ ratios.

In addition to Figures 2-9, we have listed selected calculated molecular abundances in Table 5 for eight runs, numbered 1-8. These runs, involving all three model networks, have been chosen to illustrate the effects that reaction network, time, and depletions have on the calculated molecular abundances. The parameters for each run are listed in Table 6, while the specific runs are discussed in the next section.

\section{DISCUSSION}

In the discussion section, we discuss our results by cloud, considering TMC-1 first.

\section{1. $T M C-1$}

Among the models, the NSM gives the best agreement with observed abundances in TMC-1. A glance at Figure 2 shows $\approx 80 \%$ agreement with this model, using the molecular production efficiency criterion, for a wide range of $\mathrm{C}$ and $\mathrm{O}$ elemental abundances. The best early-time solutions show generally good agreement among the four molecular groups in Table 3 for "global" depletions of 1 and 5 and for all C/O ratios for which such solutions can be distinguished from steady state solutions. These early-time solutions are closest to those obtained by Pratap et al. (1997), who used the standard low metal $\mathrm{C} / \mathrm{O}$ value but showed that a slight increase to 0.5 could account for the abundance variations seen in the 13 studied molecules. For the standard $\mathrm{C} / \mathrm{O}$ value (set 1) we find, additionally, that all of the species have calculated abundances within 2 orders of magnitude from the observed values at a best time of $3.2 \times 10^{5} \mathrm{yr}$, which is not the case for other elemental abundance ratios and times. This unique set of calculated abundances is given in Table 5 in the run 1 column. The best time is obviously not best for all molecules. As can be seen in Table 5, the calculated abundances of truly complex cyanopolyynes are rather low; these species tend to have higher values at still earlier times. Distinguishing between early time and steady state becomes more difficult with an increasing $\mathrm{C} / \mathrm{O}$ ratio, since the best early time tends to increase with an increasing $\mathrm{C} / \mathrm{O}$ ratio, as depicted in Figure 10. At steady state, with no global depletion, agreement is best for $\mathrm{C} / \mathrm{O}=1.0$ and actually worsens as $\mathrm{C} / \mathrm{O}$ increases from this value, because of overproduction of species in the $\mathrm{N}$ group. Such overproduction can be suppressed by a consideration of grain adsorption, which would, however, worsen the agreement for other molecules currently not overproduced. A global depletion of a factor of 5 at steady state improves the agreement with observation for almost all $\mathrm{C} / \mathrm{O}$ values to $\approx 75 \%$. Only for the 


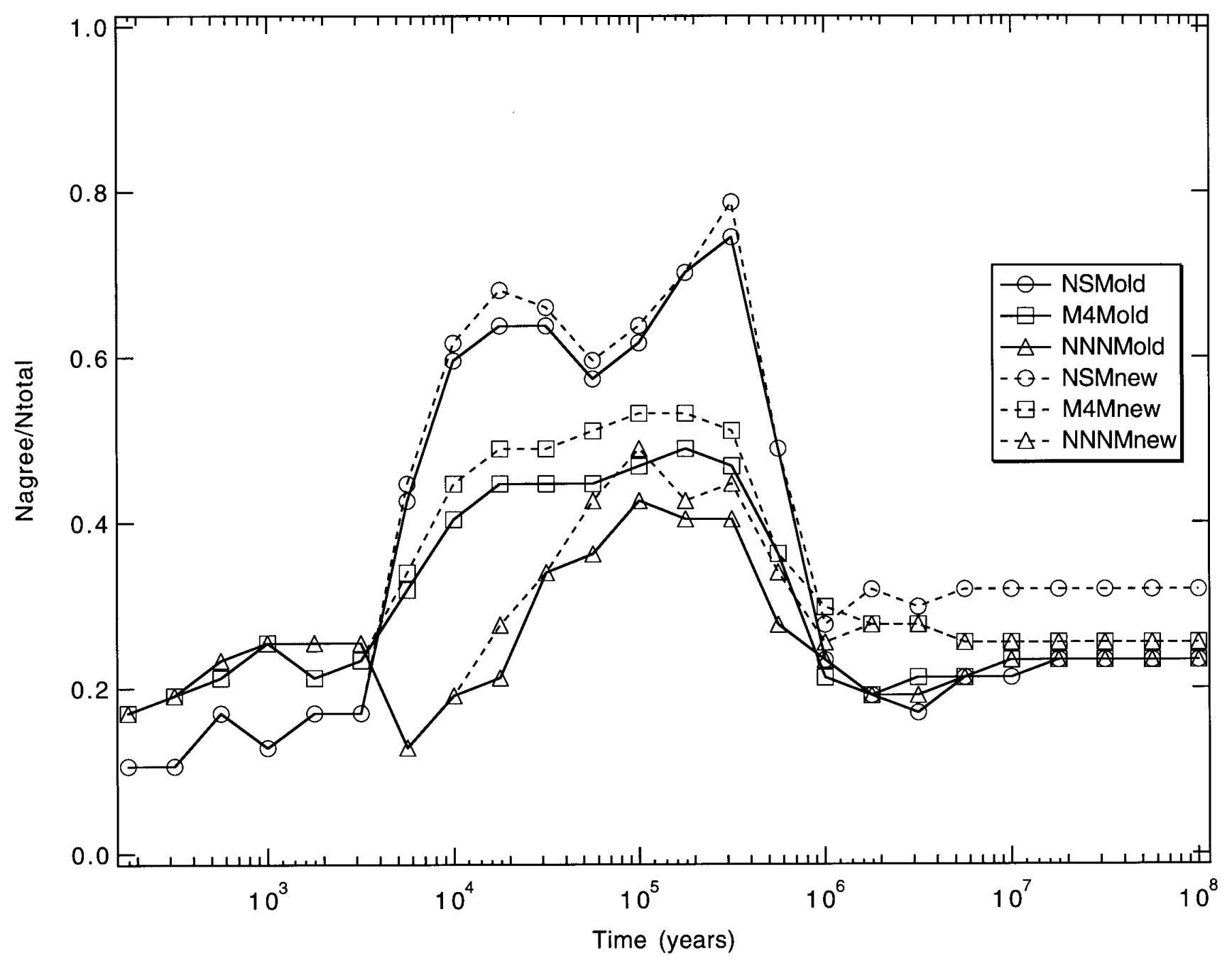

Fig. 1.-Molecular production efficiency $\left(N_{\text {agree }} / N_{\text {total }}\right)$, based on the agreement between the results of six models and observed abundances in TMC-1, is plotted vs. time for $\mathrm{C} / \mathrm{O}=0.42$ (elemental abundance set 1 in Table 1). The designations "old" and "new" refer to models without and with reaction (1).

standard value of $\mathrm{C} / \mathrm{O}=0.42$ is the agreement significantly worse than this, mainly because the $\mathrm{C}$ group of molecules (the carbon clusters and hydrocarbons) is synthesized so inefficiently. Thus, if one is willing to accept a general depletion of 5 for $\mathrm{C}$ and $\mathrm{O}$ and a $\mathrm{C} / \mathrm{O}$ ratio $>0.42$, it is no longer obvious that TMC-1 can only be represented well by earlytime solutions. This point has previously been noted by Ruffle et al. (1997) in a discussion limited to $\mathrm{HC}_{3} \mathrm{~N}$. A contrary conclusion concerning $\mathrm{HC}_{3} \mathrm{~N}$ was reached by Caselli et al. (1998), but this paper only reported on models with equal depletions of $\mathrm{C}$ and $\mathrm{O}$ from their low metal values. The early-time and steady state abundances for the case of $\mathrm{C} / \mathrm{O}=0.80$ with a common depletion of 5 are listed in the run 2 and run 3 columns in Table 5, respectively.

Although we have seen that the NSM results are in very good agreement with observed TMC-1 abundances for a variety of times and $\mathrm{C}$ and $\mathrm{O}$ elemental abundances, some species are strongly and chronically underproduced. Acetaldehyde is one such species; its calculated abundance typically lies 3 orders of magnitude lower than the observed one. The calculated underabundance of this and other oxygen-containing organic species, found typically in "dense cores," suggests strongly either that they are produced by a still undetermined gas-phase synthesis or that, even in a dark cloud such as TMC-1, desorption of molecules from grains plays some role in molecular synthesis.

When model M4M is utilized with standard elemental abundances, only about half of the species detected in TMC-1 have their calculated abundances within 1 order of magnitude from the experimental ones at early time, as can be seen in Figure 3. At steady state, the molecular production efficiency drops to $25 \%$, with essentially no molecules from the C group and only the small molecules from the $\mathrm{N}$ group in agreement with observation. For example, the calculated abundances of $\mathrm{CH}_{2} \mathrm{CN}, \mathrm{C}_{2} \mathrm{H}_{3} \mathrm{CN}, \mathrm{HC}_{5} \mathrm{~N}$, $\mathrm{HC}_{7} \mathrm{~N}, \mathrm{HC}_{9} \mathrm{~N}, \mathrm{C}_{6} \mathrm{H}$, and others are more than 3 orders of magnitude lower than observed for most times. The negative effect of rapid neutral-neutral reactions on the synthesis of larger molecules has been well documented for standard elemental abundances (Bettens et al. 1995). A depletion of 5 for both $\mathrm{C}$ and $\mathrm{O}$ results in some improvement at both early time and, less obviously, at steady state. An increase in the $\mathrm{C} / \mathrm{O}$ abundance ratio is helpful for general depletions of both 1 and 5, especially at steady state. This improvement does not extend to the O-containing molecules methanol and acetaldehyde nor to the S-containing molecule $\mathrm{SO}_{2}$. At best, a molecular production efficiency of $\approx 70 \%$ can be achieved; this occurs for $\mathrm{C} / \mathrm{O}=1.2$ at early time. 


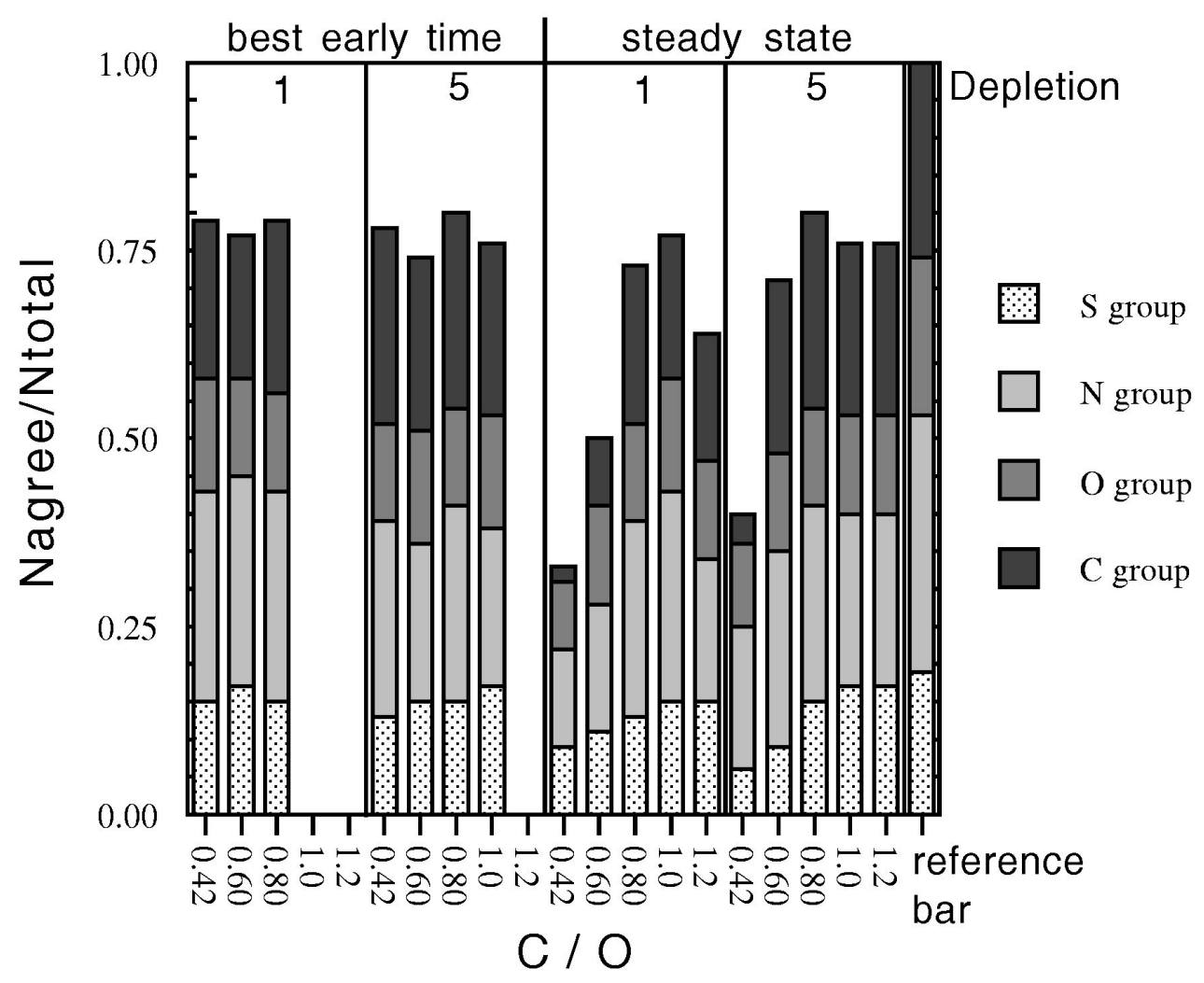

Fig. 2.-Molecular production efficiency for the molecules observed in TMC-1, obtained with the NSM. Each vertical bar is an accumulation for the four groups of molecules studied and, as a whole, gives the overall production efficiency as a function of $\mathrm{C} / \mathrm{O}$ elemental abundance ratio and general depletion factor for $\mathrm{C}$ and $\mathrm{O}$. A reference bar shows the maximum possible contribution from each group, which would give an overall production efficiency of 1 . The best early times (yr) referred to are 3.2 (5), $3.2(5)$ to $5.6(5), 3.2$ (6) for $\mathrm{C} / \mathrm{O}=0.42,0.60,0.80$, respectively, and no depletion; and 1.8 (5), $1.8(5), 3.2$ (5), 3.2 (5), and $3.2(6)$ for $\mathrm{C} / \mathrm{O}=0.42,0.60,0.80,1.0$, respectively, and a depletion of 5.

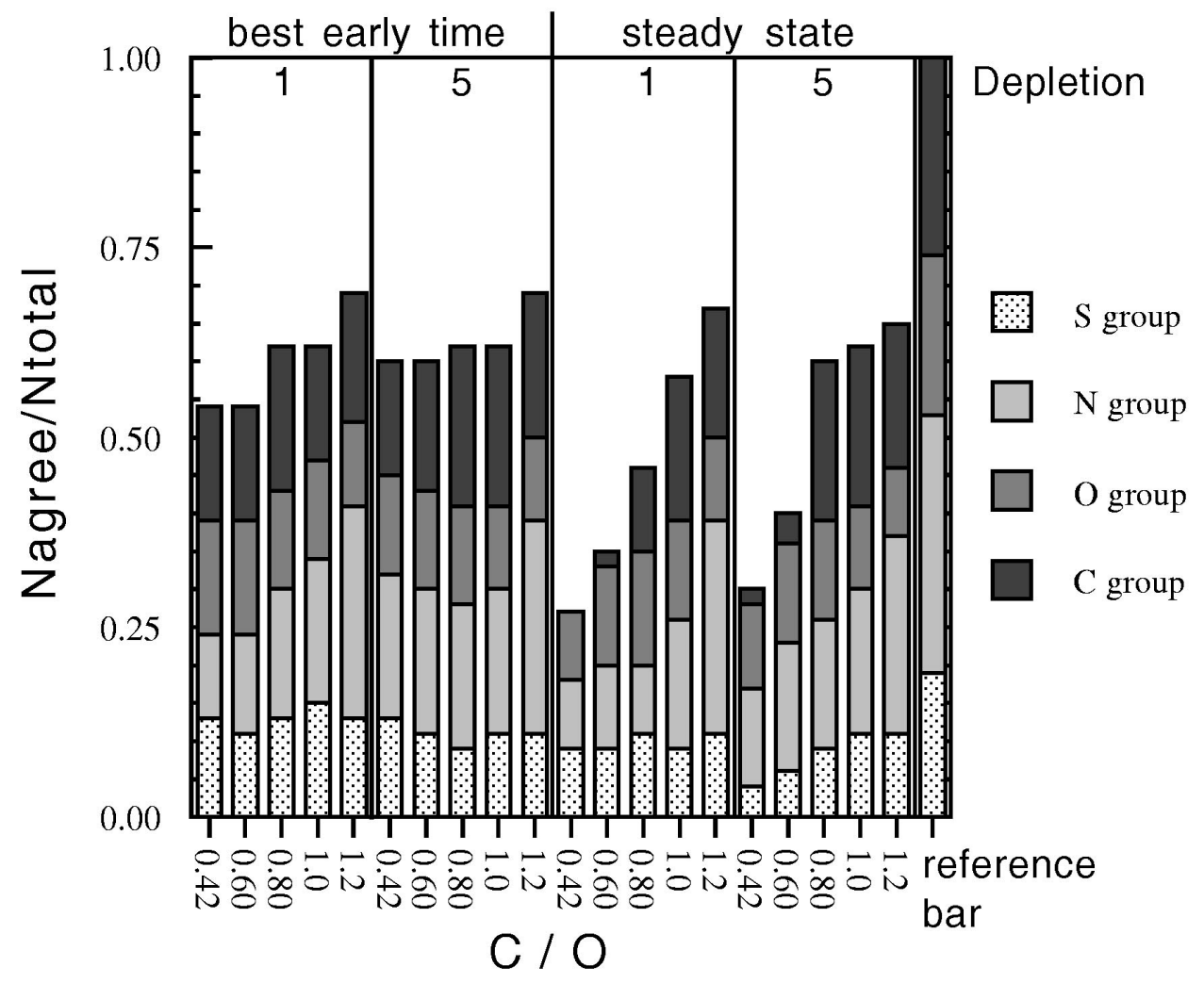

Fig. 3.-Same as Fig. 2, except obtained with the M4M. The best early times (yr) referred to are $1.0(5)$ to $1.8(5), 3.2(5), 5.6(4), 3.2(4)$ and $1.0(5)$ and $1.8(5)$ for $\mathrm{C} / \mathrm{O}=0.42,0.60,0.80,1.0,1.2$, respectively, and no depletion; and 1.8 (4), 1.8 (4) and $5.6(4), 5.6(4), 1.8(4)$ and $5.6(4)$ and $>3.2(5), 1.8(5)$ to $5.6(5)$ for $\mathrm{C} / \mathrm{O}=0.42,0.6,0.80,1.0,1.2$, respectively, and a depletion of 5 . 


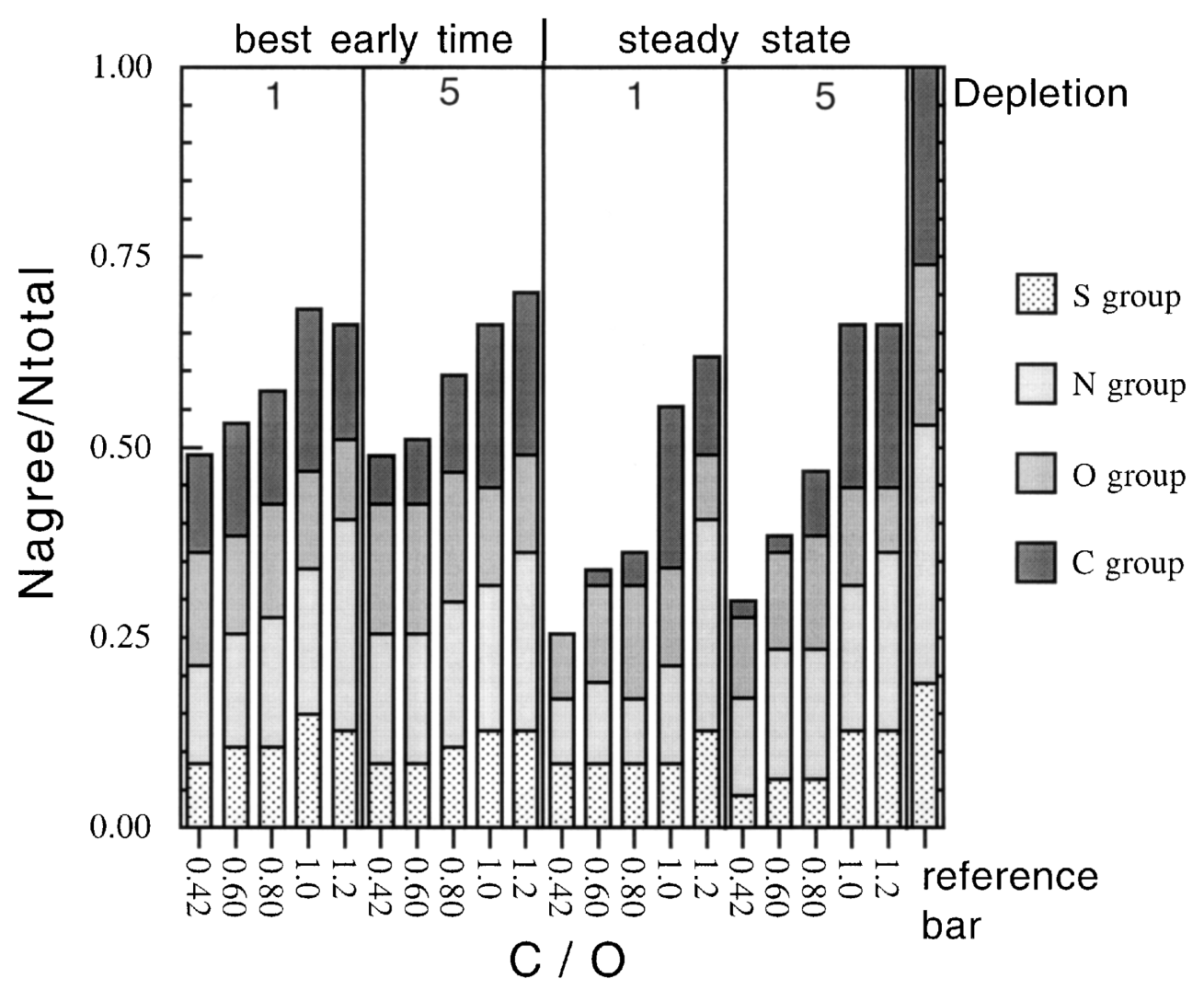

FIG. 4.-Same as Fig. 2, except obtained with the NNNM. The best early times (yr) referred to are 1.0 (5), $1.8(5), 1.8(5), 3.2(5), 3.2(5)$ for C/O = 0.42, 0.60 , $0.80,1.0,1.2$, respectively, and no depletion; and $3.2(4), 1.0(5)$ to $1.8(5), 1.8(5),>1.0(6), 5.6(5)$ for $\mathrm{C} / \mathrm{O}=0.42,0.60,0.80,1.0,1.2$, respectively, and a depletion of 5 .

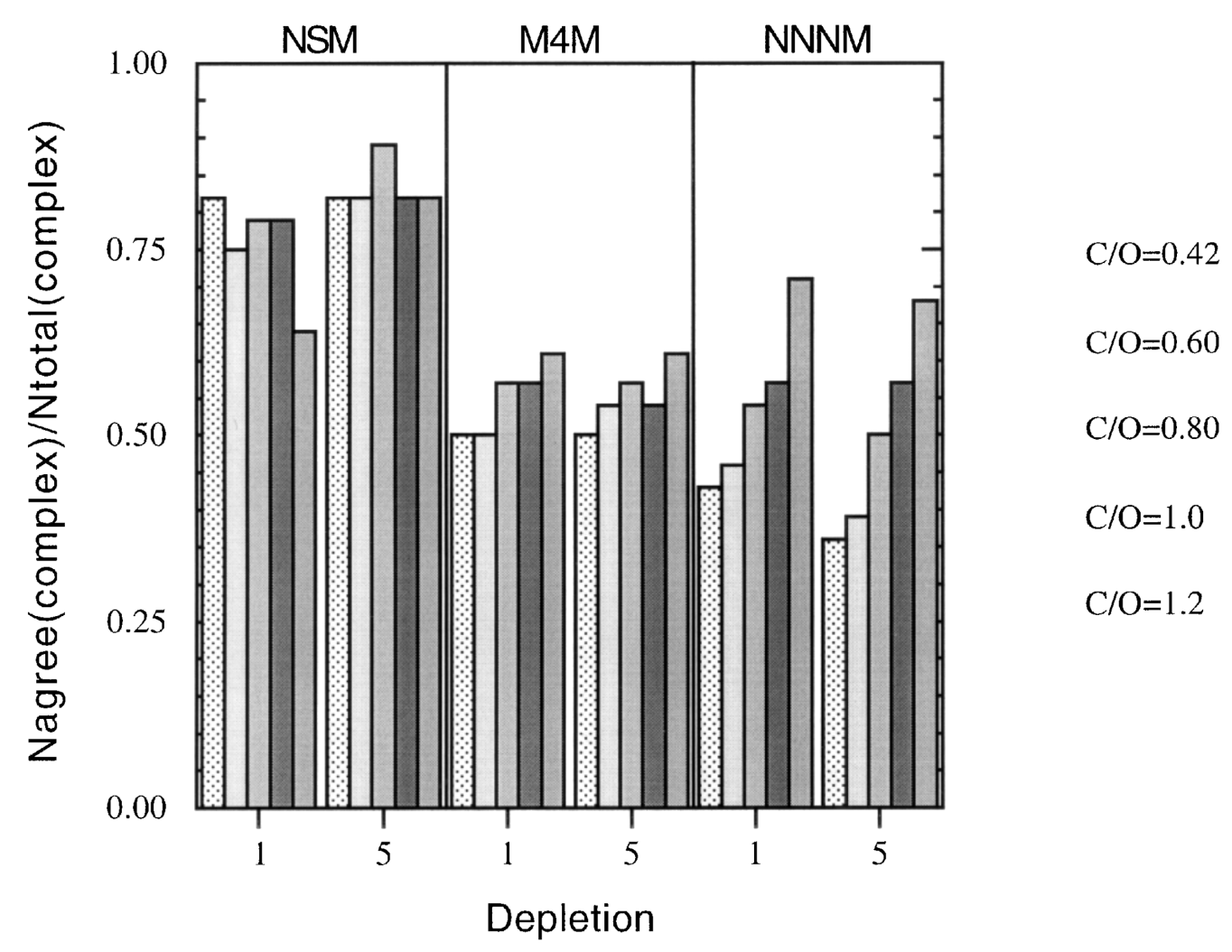

Fig. 5.-Best complex molecular production efficiencies for the molecules observed in TMC-1, obtained with the NSM, M4M, and NNNM, for assorted $\mathrm{C} / \mathrm{O}$ values (given in different shades of gray) and common depletions of 1 and 5 for $\mathrm{C}$ and $\mathrm{O}$. The best agreement times are early times except for the richest C/O ratios for the NSM. 


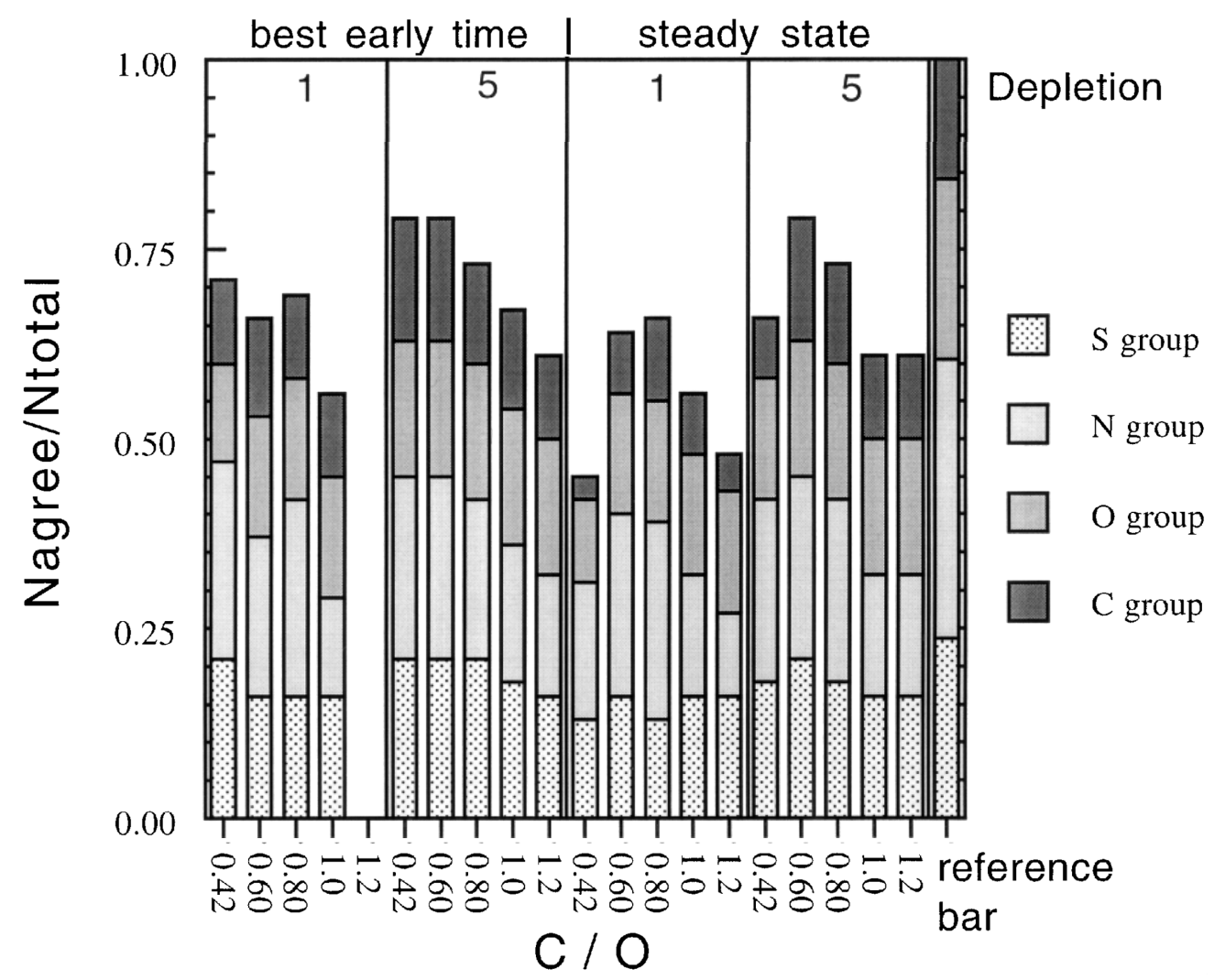

FIG. 6.-Molecular production efficiency for the molecules observed in L134N, obtained with the NSM. Each vertical bar is an accumulation for the four groups of molecules studied and, as a whole, gives the overall production efficiency as a function of $\mathrm{C} / \mathrm{O}$ elemental abundance ratio and general depletion factor for $\mathrm{C}$ and $\mathrm{O}$. A reference bar shows the maximum possible contribution from each group, which would give an overall production efficiency of 1 . The best early times (yr) referred to are 5.6 (5), 5.6 (5), 3.2 (6), $>5.6(5)$ for $\mathrm{C} / \mathrm{O}=0.42,0.60,0.80,1.0$, respectively, and no depletion; and 3.2 (5), $>5.6(5), 5.6(5)$ and $>1.8(6), 5.6(5),>1.0(6)$ for $\mathrm{C} / \mathrm{O}=0.42,0.60,0.8,1.0,1.2$, respectively, and a depletion of 5 .

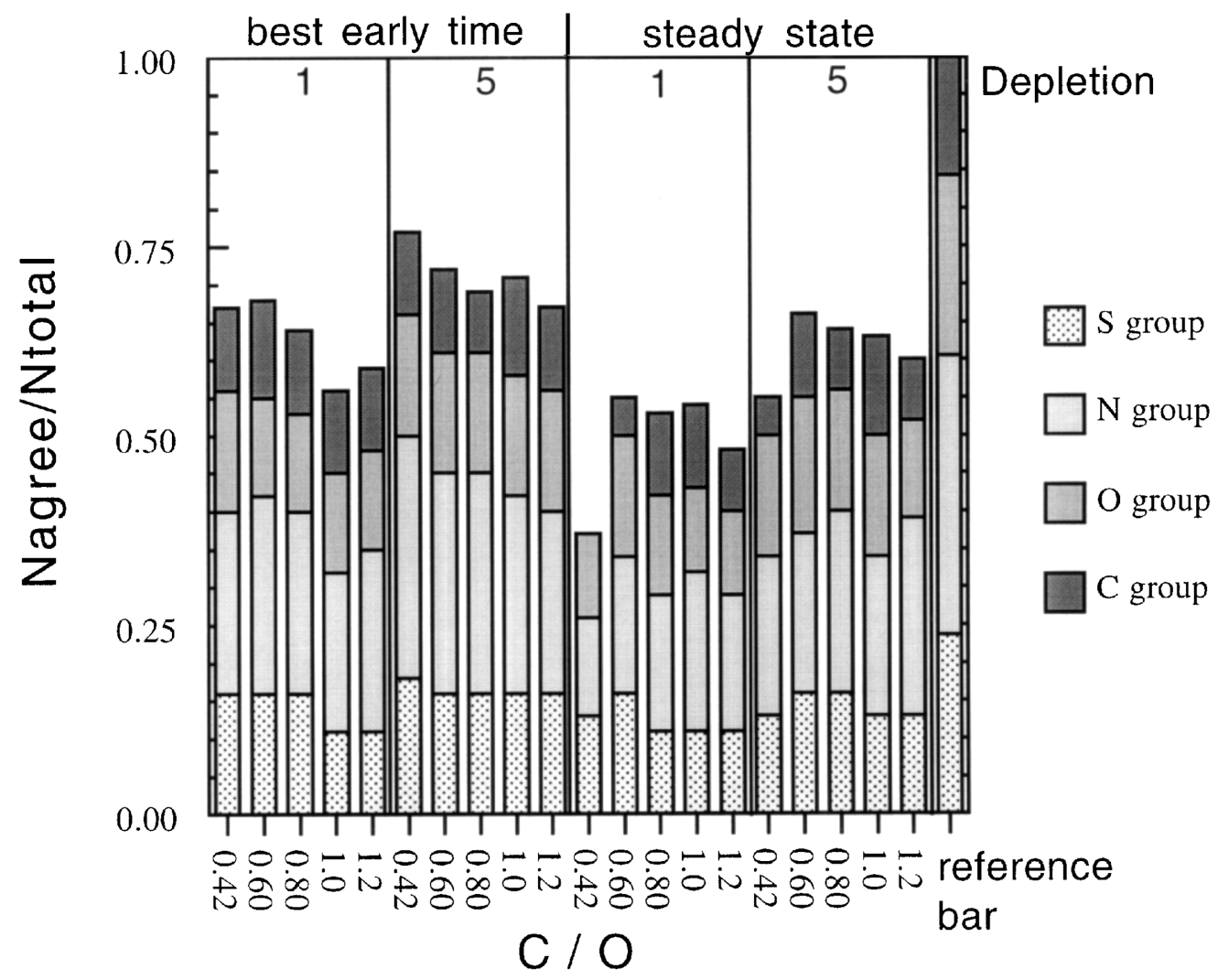

Fig. 7.-Same as Fig. 6, except obtained with the M4M. The best early times (yr) referred to are 1.8 (5) to 3.2 (5), $1.8(5), 1.0(5)$ to $5.6(5), 1.8(4)$ to $1.0(5), 5.6$ (4) for $\mathrm{C} / \mathrm{O}=0.42,0.60,0.80,1.0,1.2$, respectively, and no depletion; and 5.6 (4) to $1.8(5), 3.2(5)$ to $5.6(5), 5.6(5), 3.2(5), 5.6(4)$ to $1.8(5)$ for $\mathrm{C} / \mathrm{O}=0.42,0.60$, $0.80,1.0,1.2$, respectively, and a depletion of 5 . 


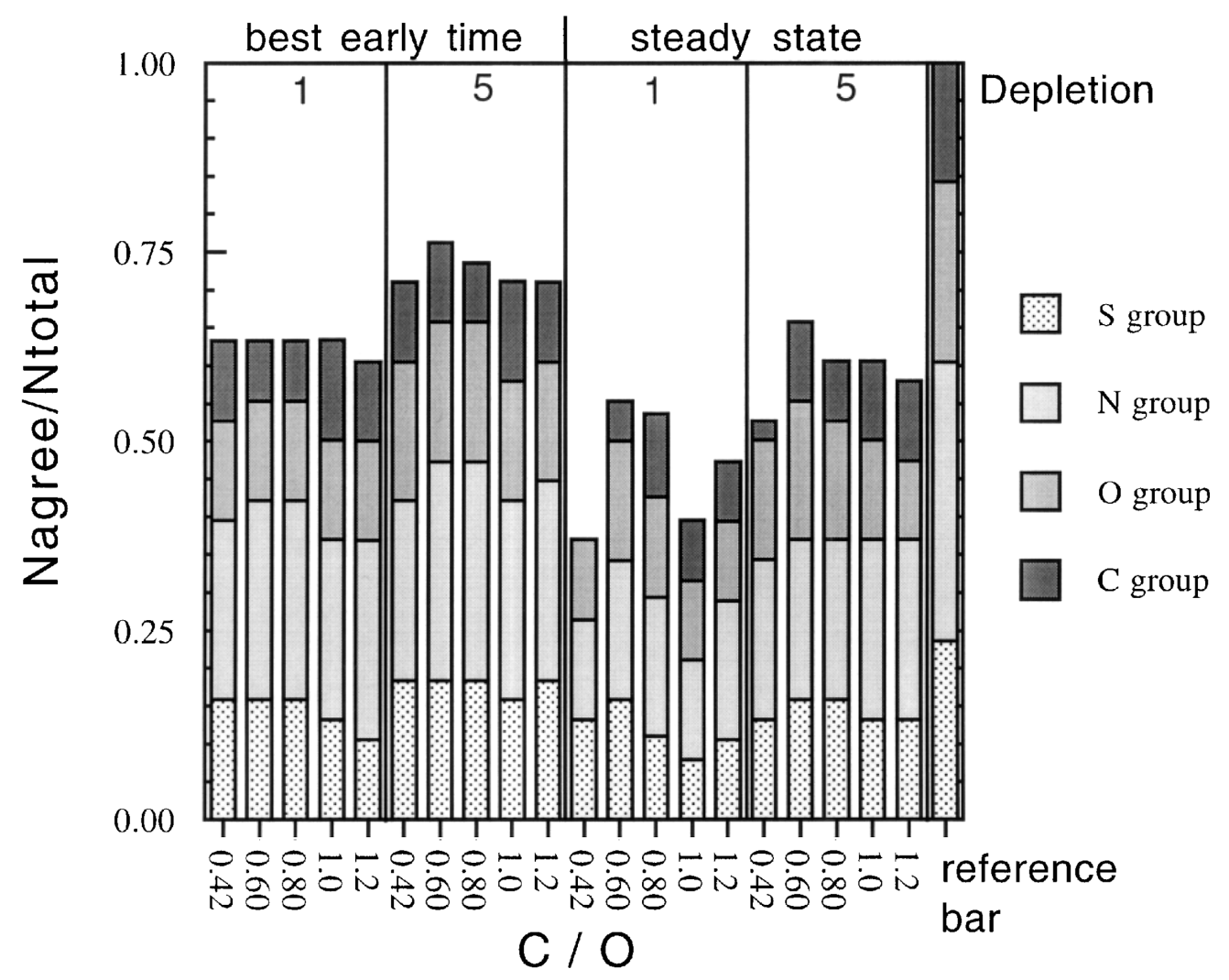

FIG. 8.-Same as Fig. 6, except obtained with the NNNM. The best early times (yr) referred to are 1.8 (5), 1.8 (5) to 3.2 (5), 1.8 (5) to 3.2 (5), 3.2 (5), 1.8 (5) for $\mathrm{C} / \mathrm{O}=0.42,0.60,0.80,1.0,1.2$, respectively, and no depletion; and 5.6 (4), $1.0(5), 5.6(4), 5.6(5), 1.8(5)$ for $\mathrm{C} / \mathrm{O}=0.42,0.60,0.80,1.0,1.2$, respectively, and a depletion of 5 .

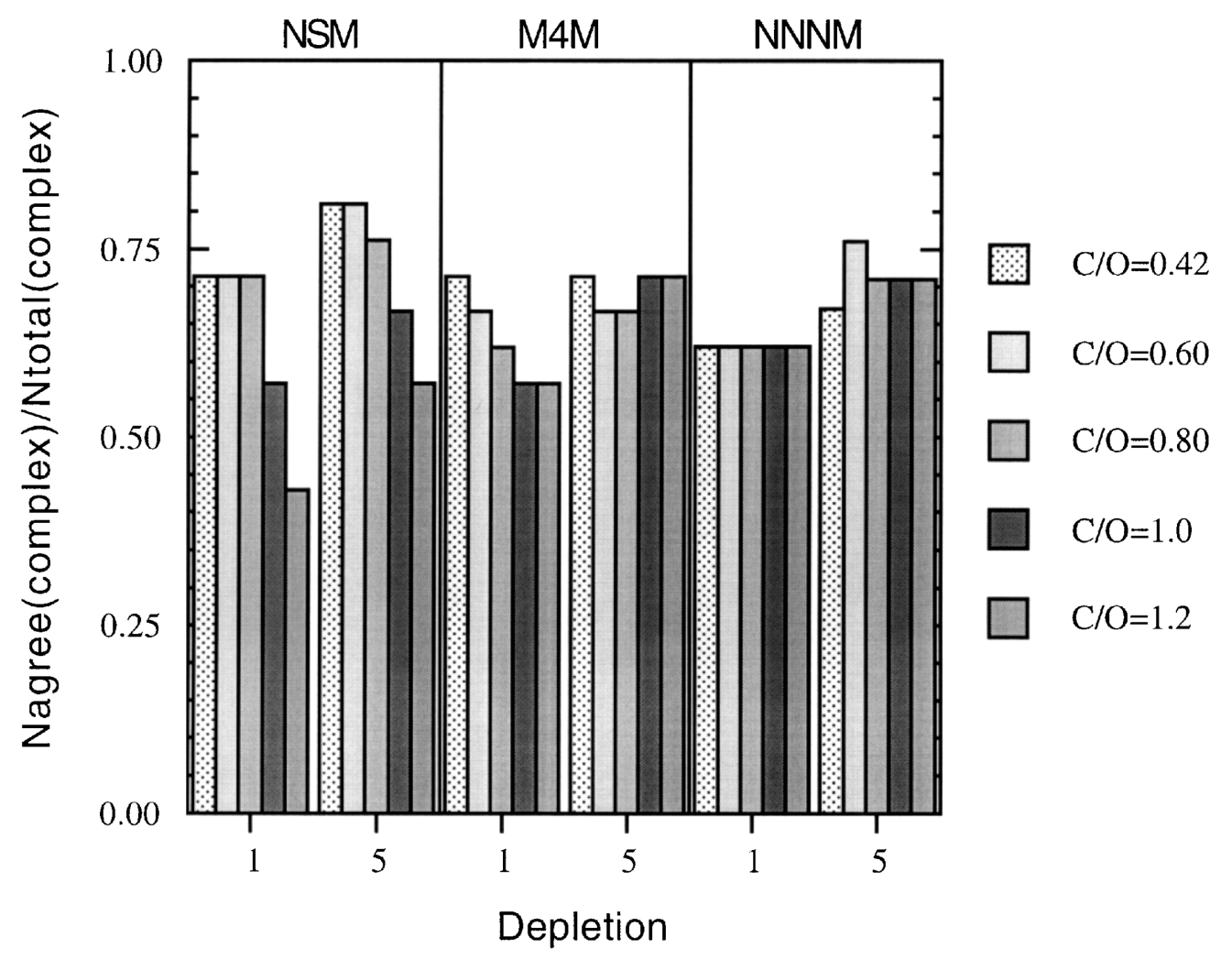

FIG. 9.-Same as Fig. 5, except for L134N. The best agreement times are all early times. 
TABLE 5

Calculated Fractional Abundances of Species Observed in TMC-1 and L134N with Respect to $\mathrm{H}_{2}$

\begin{tabular}{|c|c|c|c|c|c|c|c|c|}
\hline \multirow[b]{2}{*}{ SPECIES } & \multicolumn{8}{|c|}{$\operatorname{RuN}^{a}$} \\
\hline & 1 & 2 & 3 & 4 & 5 & 6 & 7 & 8 \\
\hline & $6.0 \mathrm{E}-09$ & $4.7 \mathrm{E}-08$ & $9.7 \mathrm{E}-08$ & $8.8 \mathrm{E}-11$ & $1.5 \mathrm{E}-09$ & $6.3 \mathrm{E}-09$ & $3.2 \mathrm{E}-09$ & $3.1 \mathrm{E}-08$ \\
\hline $\mathrm{CH} \ldots \ldots \ldots \ldots$ & $9.1 \mathrm{E}-10$ & $6.6 \mathrm{E}-09$ & $7.0 \mathrm{E}-09$ & $1.8 \mathrm{E}-11$ & $1.6 \mathrm{E}-09$ & $3.4 \mathrm{E}-09$ & $1.5 \mathrm{E}-09$ & $7.6 \mathrm{E}-09$ \\
\hline $\mathrm{CN} \ldots \ldots$ & $5.5 \mathrm{E}-08$ & $4.8 \mathrm{E}-07$ & $2.9 \mathrm{E}-07$ & $3.6 \mathrm{E}-09$ & $6.3 \mathrm{E}-09$ & $1.4 \mathrm{E}-08$ & $9.0 \mathrm{E}-09$ & $5.5 \mathrm{E}-08$ \\
\hline $\mathrm{CO} \ldots \ldots \ldots \ldots$ & $1.4 \mathrm{E}-04$ & $2.1 \mathrm{E}-05$ & $2.4 \mathrm{E}-05$ & $2.9 \mathrm{E}-05$ & $2.5 \mathrm{E}-05$ & $1.6 \mathrm{E}-05$ & $2.8 \mathrm{E}-05$ & $1.7 \mathrm{E}-05$ \\
\hline $\mathrm{CS} \ldots \ldots \ldots \ldots$ & $4.2 \mathrm{E}-09$ & $6.5 \mathrm{E}-09$ & $7.6 \mathrm{E}-09$ & $2.6 \mathrm{E}-10$ & $7.4 \mathrm{E}-10$ & $1.9 \mathrm{E}-09$ & $1.4 \mathrm{E}-09$ & $5.3 \mathrm{E}-09$ \\
\hline NO $\ldots \ldots \ldots \ldots$ & $5.6 \mathrm{E}-08$ & $7.8 \mathrm{E}-08$ & $6.2 \mathrm{E}-08$ & $1.7 \mathrm{E}-07$ & $1.5 \mathrm{E}-07$ & $7.4 \mathrm{E}-08$ & $5.6 \mathrm{E}-08$ & $3.9 \mathrm{E}-08$ \\
\hline $\mathrm{OH}, \ldots \ldots \ldots \ldots$ & $5.8 \mathrm{E}-09$ & $2.1 \mathrm{E}-08$ & $2.1 \mathrm{E}-08$ & $1.2 \mathrm{E}-08$ & $2.4 \mathrm{E}-08$ & $2.2 \mathrm{E}-08$ & $2.1 \mathrm{E}-08$ & $2.0 \mathrm{E}-08$ \\
\hline $\mathrm{SO}, \ldots \ldots \ldots \ldots$ & $1.8 \mathrm{E}-09$ & $1.6 \mathrm{E}-09$ & $1.3 \mathrm{E}-09$ & $2.2 \mathrm{E}-08$ & $2.7 \mathrm{E}-09$ & $6.8 \mathrm{E}-10$ & $7.6 \mathrm{E}-10$ & $3.0 \mathrm{E}-10$ \\
\hline $\mathrm{C}_{2} \mathrm{H} \ldots \ldots \ldots \ldots$ & $8.6 \mathrm{E}-09$ & $3.5 \mathrm{E}-08$ & $2.3 \mathrm{E}-08$ & $1.9 \mathrm{E}-10$ & $8.5 \mathrm{E}-10$ & $1.8 \mathrm{E}-09$ & $1.1 \mathrm{E}-09$ & $5.4 \mathrm{E}-09$ \\
\hline $\mathrm{C}_{2} \mathrm{~S} \ldots \ldots \ldots \ldots$ & $1.2 \mathrm{E}-09$ & $8.0 \mathrm{E}-10$ & $7.1 \mathrm{E}-10$ & $2.9 \mathrm{E}-11$ & $3.2 \mathrm{E}-10$ & $1.8 \mathrm{E}-10$ & $1.2 \mathrm{E}-10$ & $3.3 \mathrm{E}-10$ \\
\hline $\mathrm{C}_{2} \mathrm{O} \ldots \ldots \ldots \ldots$ & $8.5 \mathrm{E}-11$ & $1.9 \mathrm{E}-11$ & $2.0 \mathrm{E}-11$ & $1.8 \mathrm{E}-12$ & $2.0 \mathrm{E}-10$ & $1.3 \mathrm{E}-10$ & $8.2 \mathrm{E}-11$ & $6.6 \mathrm{E}-11$ \\
\hline $\mathrm{H}_{2} \mathrm{~S} \ldots \ldots \ldots \ldots$ & $3.9 \mathrm{E}-11$ & $2.3 \mathrm{E}-10$ & $3.0 \mathrm{E}-10$ & $4.6 \mathrm{E}-11$ & $1.9 \mathrm{E}-10$ & $1.6 \mathrm{E}-10$ & $1.9 \mathrm{E}-10$ & $2.6 \mathrm{E}-10$ \\
\hline $\mathrm{HCN} \ldots \ldots \ldots \ldots$ & $5.1 \mathrm{E}-08$ & $4.6 \mathrm{E}-07$ & $2.0 \mathrm{E}-07$ & $5.4 \mathrm{E}-09$ & $2.8 \mathrm{E}-08$ & $6.5 \mathrm{E}-08$ & $1.9 \mathrm{E}-08$ & $1.1 \mathrm{E}-07$ \\
\hline HNC $\ldots \ldots \ldots \ldots$ & $2.8 \mathrm{E}-08$ & $4.0 \mathrm{E}-07$ & $1.8 \mathrm{E}-07$ & $5.5 \mathrm{E}-09$ & $3.0 \mathrm{E}-08$ & $5.2 \mathrm{E}-08$ & $1.9 \mathrm{E}-08$ & $9.0 \mathrm{E}-08$ \\
\hline OCS $\ldots \ldots \ldots \ldots$ & $1.2 \mathrm{E}-09$ & $8.3 \mathrm{E}-10$ & $4.3 \mathrm{E}-10$ & $2.0 \mathrm{E}-10$ & $1.4 \mathrm{E}-10$ & $2.3 \mathrm{E}-10$ & $7.3 \mathrm{E}-11$ & $2.2 \mathrm{E}-10$ \\
\hline $\mathrm{SO}_{2} \ldots \ldots \ldots \ldots$ & $3.3 \mathrm{E}-10$ & $2.9 \mathrm{E}-11$ & $1.4 \mathrm{E}-11$ & $5.3 \mathrm{E}-09$ & $5.6 \mathrm{E}-11$ & $1.2 \mathrm{E}-11$ & $6.6 \mathrm{E}-12$ & $2.4 \mathrm{E}-12$ \\
\hline $\mathrm{C}_{3} \mathrm{H} \ldots \ldots \ldots$ & $5.5 \mathrm{E}-09$ & $4.3 \mathrm{E}-09$ & $4.8 \mathrm{E}-09$ & $2.0 \mathrm{E}-11$ & $1.9 \mathrm{E}-09$ & $2.9 \mathrm{E}-09$ & $1.1 \mathrm{E}-09$ & $7.3 \mathrm{E}-09$ \\
\hline $\mathrm{C}_{3} \mathrm{~N} \ldots \ldots \ldots \ldots$ & $4.5 \mathrm{E}-09$ & $2.4 \mathrm{E}-08$ & $1.4 \mathrm{E}-08$ & $2.0 \mathrm{E}-11$ & $1.0 \mathrm{E}-09$ & $1.1 \mathrm{E}-09$ & $3.6 \mathrm{E}-10$ & $2.7 \mathrm{E}-09$ \\
\hline $\mathrm{C}_{3} \mathrm{O} \ldots \ldots \ldots$ & $5.2 \mathrm{E}-11$ & $1.2 \mathrm{E}-11$ & $1.7 \mathrm{E}-11$ & $2.2 \mathrm{E}-13$ & $7.9 \mathrm{E}-10$ & $7.4 \mathrm{E}-10$ & $3.3 \mathrm{E}-10$ & $8.0 \mathrm{E}-10$ \\
\hline $\mathrm{C}_{3} \mathrm{~S} \ldots \ldots \ldots \ldots$ & $1.9 \mathrm{E}-10$ & $1.5 \mathrm{E}-10$ & $1.5 \mathrm{E}-10$ & $6.1 \mathrm{E}-13$ & $1.1 \mathrm{E}-10$ & $2.9 \mathrm{E}-11$ & $2.0 \mathrm{E}-11$ & $5.8 \mathrm{E}-11$ \\
\hline $\mathrm{H}_{2} \mathrm{CO} \ldots \ldots \ldots$ & $2.5 \mathrm{E}-08$ & $6.0 \mathrm{E}-09$ & $6.8 \mathrm{E}-09$ & $2.3 \mathrm{E}-09$ & $9.2 \mathrm{E}-09$ & $6.7 \mathrm{E}-08$ & $1.3 \mathrm{E}-08$ & $4.4 \mathrm{E}-08$ \\
\hline $\mathrm{H}_{2} \mathrm{CS} \ldots \ldots \ldots$ & $1.4 \mathrm{E}-09$ & $5.9 \mathrm{E}-10$ & $4.2 \mathrm{E}-10$ & $1.3 \mathrm{E}-10$ & $8.0 \mathrm{E}-11$ & $2.9 \mathrm{E}-10$ & $1.7 \mathrm{E}-10$ & $5.6 \mathrm{E}-10$ \\
\hline $\mathrm{NH}_{3} \ldots \ldots \ldots \ldots$ & $8.2 \mathrm{E}-08$ & $1.9 \mathrm{E}-07$ & $1.9 \mathrm{E}-07$ & $2.3 \mathrm{E}-07$ & $5.0 \mathrm{E}-07$ & $4.8 \mathrm{E}-07$ & $1.8 \mathrm{E}-07$ & $4.5 \mathrm{E}-07$ \\
\hline $\mathrm{CH}_{2} \mathrm{CN} \ldots \ldots \ldots$ & $9.2 \mathrm{E}-09$ & $2.6 \mathrm{E}-08$ & $6.4 \mathrm{E}-09$ & $5.6 \mathrm{E}-11$ & $6.3 \mathrm{E}-12$ & $1.0 \mathrm{E}-10$ & $1.4 \mathrm{E}-11$ & $3.3 \mathrm{E}-10$ \\
\hline $\mathrm{CH}_{2} \mathrm{CO} \ldots \ldots \ldots$ & $9.3 \mathrm{E}-09$ & $1.4 \mathrm{E}-09$ & $5.3 \mathrm{E}-10$ & $2.3 \mathrm{E}-10$ & $1.9 \mathrm{E}-10$ & $1.3 \mathrm{E}-09$ & $8.3 \mathrm{E}-11$ & $5.7 \mathrm{E}-10$ \\
\hline $\mathrm{C}_{3} \mathrm{H}_{2} \ldots \ldots \ldots$ & $5.2 \mathrm{E}-09$ & $5.4 \mathrm{E}-09$ & $6.6 \mathrm{E}-09$ & $2.6 \mathrm{E}-11$ & $8.6 \mathrm{E}-09$ & $1.2 \mathrm{E}-09$ & $8.8 \mathrm{E}-10$ & $2.3 \mathrm{E}-09$ \\
\hline $\mathrm{C}_{4} \mathrm{H} \ldots \ldots \ldots \ldots$ & $8.0 \mathrm{E}-09$ & $8.7 \mathrm{E}-09$ & $6.8 \mathrm{E}-09$ & $5.5 \mathrm{E}-12$ & $7.0 \mathrm{E}-10$ & $4.2 \mathrm{E}-10$ & $1.7 \mathrm{E}-10$ & $1.5 \mathrm{E}-09$ \\
\hline $\mathrm{HCOOH} \ldots . .$. & $3.6 \mathrm{E}-09$ & $6.1 \mathrm{E}-10$ & $4.5 \mathrm{E}-10$ & $3.0 \mathrm{E}-09$ & $4.8 \mathrm{E}-10$ & $3.0 \mathrm{E}-10$ & $2.8 \mathrm{E}-10$ & $1.6 \mathrm{E}-10$ \\
\hline $\mathrm{HC}_{3} \mathrm{~N} \ldots \ldots \ldots$ & $2.2 \mathrm{E}-08$ & $5.8 \mathrm{E}-08$ & $3.5 \mathrm{E}-08$ & $1.1 \mathrm{E}-10$ & $5.4 \mathrm{E}-10$ & $5.6 \mathrm{E}-10$ & $1.1 \mathrm{E}-10$ & $1.7 \mathrm{E}-09$ \\
\hline $\mathrm{CH}_{3} \mathrm{CN} \ldots \ldots \ldots$ & $5.0 \mathrm{E}-10$ & $5.5 \mathrm{E}-09$ & $1.4 \mathrm{E}-09$ & $1.3 \mathrm{E}-12$ & $3.7 \mathrm{E}-11$ & $1.3 \mathrm{E}-09$ & $4.0 \mathrm{E}-11$ & $2.3 \mathrm{E}-09$ \\
\hline $\mathrm{C}_{4} \mathrm{H}_{2} \ldots \ldots \ldots \ldots$ & $4.2 \mathrm{E}-09$ & $5.0 \mathrm{E}-10$ & $6.5 \mathrm{E}-10$ & $3.4 \mathrm{E}-11$ & $3.0 \mathrm{E}-10$ & $7.9 \mathrm{E}-11$ & $3.2 \mathrm{E}-11$ & $2.3 \mathrm{E}-10$ \\
\hline $\mathrm{C}_{5}^{4} \mathrm{H} \ldots \ldots \ldots \ldots$ & $2.2 \mathrm{E}-10$ & $2.5 \mathrm{E}-10$ & $2.0 \mathrm{E}-10$ & $4.7 \mathrm{E}-14$ & $1.5 \mathrm{E}-10$ & $2.5 \mathrm{E}-11$ & $3.1 \mathrm{E}-12$ & $1.2 \mathrm{E}-10$ \\
\hline $\mathrm{CH}_{3} \mathrm{OH} \ldots \ldots \ldots$ & $5.0 \mathrm{E}-10$ & $3.5 \mathrm{E}-10$ & $7.7 \mathrm{E}-11$ & $3.2 \mathrm{E}-11$ & $3.4 \mathrm{E}-11$ & $4.1 \mathrm{E}-10$ & $1.7 \mathrm{E}-11$ & $1.7 \mathrm{E}-10$ \\
\hline $\mathrm{CH}_{3} \mathrm{CHO} \ldots \ldots$ & $9.7 \mathrm{E}-12$ & $5.7 \mathrm{E}-13$ & $3.9 \mathrm{E}-13$ & $1.5 \mathrm{E}-12$ & $8.2 \mathrm{E}-13$ & $5.0 \mathrm{E}-13$ & $9.0 \mathrm{E}-14$ & $4.3 \mathrm{E}-13$ \\
\hline $\mathrm{C}_{2} \mathrm{H}_{3} \mathrm{CN} \ldots \ldots \ldots$ & $3.6 \mathrm{E}-10$ & $5.8 \mathrm{E}-10$ & $2.6 \mathrm{E}-10$ & $1.8 \mathrm{E}-12$ & $2.0 \mathrm{E}-12$ & $2.2 \mathrm{E}-12$ & $4.7 \mathrm{E}-13$ & $1.4 \mathrm{E}-11$ \\
\hline $\mathrm{C}_{3} \mathrm{H}_{4} \ldots \ldots \ldots$ & $2.9 \mathrm{E}-09$ & $2.0 \mathrm{E}-09$ & $1.1 \mathrm{E}-09$ & $2.4 \mathrm{E}-12$ & $1.3 \mathrm{E}-10$ & $2.7 \mathrm{E}-11$ & $1.7 \mathrm{E}-11$ & $8.3 \mathrm{E}-11$ \\
\hline $\mathrm{C}_{6} \mathrm{H} \ldots \ldots \ldots \ldots$ & $1.0 \mathrm{E}-10$ & $9.2 \mathrm{E}-11$ & $6.7 \mathrm{E}-11$ & $4.3 \mathrm{E}-14$ & $8.6 \mathrm{E}-11$ & $4.1 \mathrm{E}-12$ & $6.7 \mathrm{E}-13$ & $2.4 \mathrm{E}-11$ \\
\hline $\mathrm{HC}_{5} \mathrm{~N} \ldots \ldots \ldots$ & $7.9 \mathrm{E}-10$ & $1.9 \mathrm{E}-09$ & $8.3 \mathrm{E}-10$ & $4.6 \mathrm{E}-13$ & $1.2 \mathrm{E}-10$ & $1.1 \mathrm{E}-11$ & $7.0 \mathrm{E}-13$ & $3.9 \mathrm{E}-11$ \\
\hline $\mathrm{C}_{6} \mathrm{H}_{2} \ldots \ldots \ldots$ & $4.6 \mathrm{E}-10$ & $3.5 \mathrm{E}-11$ & $5.6 \mathrm{E}-11$ & $2.2 \mathrm{E}-12$ & $1.5 \mathrm{E}-10$ & $5.3 \mathrm{E}-12$ & $3.9 \mathrm{E}-12$ & $2.1 \mathrm{E}-11$ \\
\hline $\mathrm{CH}_{3} \mathrm{C}_{3} \mathrm{~N} \ldots \ldots \ldots$ & $9.7 \mathrm{E}-11$ & $1.8 \mathrm{E}-10$ & $6.1 \mathrm{E}-11$ & $9.6 \mathrm{E}-14$ & $4.2 \mathrm{E}-12$ & $6.5 \mathrm{E}-12$ & $5.1 \mathrm{E}-13$ & $1.4 \mathrm{E}-11$ \\
\hline $\mathrm{CH}_{3} \mathrm{C}_{4} \mathrm{H} \ldots \ldots$ & $1.4 \mathrm{E}-09$ & $9.4 \mathrm{E}-10$ & $3.4 \mathrm{E}-10$ & $3.1 \mathrm{E}-13$ & $2.3 \mathrm{E}-11$ & $8.6 \mathrm{E}-12$ & $4.8 \mathrm{E}-12$ & $3.2 \mathrm{E}-11$ \\
\hline $\mathrm{HC}_{7} \mathrm{~N} \ldots \ldots \ldots$ & $5.6 \mathrm{E}-11$ & $1.7 \mathrm{E}-10$ & $8.0 \mathrm{E}-11$ & $2.1 \mathrm{E}-14$ & $2.0 \mathrm{E}-11$ & $4.4 \mathrm{E}-13$ & $5.1 \mathrm{E}-14$ & $3.2 \mathrm{E}-12$ \\
\hline $\mathrm{HC}_{9} \mathrm{~N} \ldots \ldots \ldots$ & $3.3 \mathrm{E}-12$ & $8.4 \mathrm{E}-12$ & $2.9 \mathrm{E}-12$ & $3.2 \mathrm{E}-16$ & $2.3 \mathrm{E}-12$ & $5.5 \mathrm{E}-15$ & $3.0 \mathrm{E}-16$ & $6.1 \mathrm{E}-14$ \\
\hline $\mathrm{HCO}^{+} \ldots \ldots \ldots$ & $7.6 \mathrm{E}-09$ & $2.1 \mathrm{E}-09$ & $3.7 \mathrm{E}-09$ & $3.1 \mathrm{E}-09$ & $4.7 \mathrm{E}-09$ & $3.0 \mathrm{E}-09$ & $5.5 \mathrm{E}-09$ & $3.1 \mathrm{E}-09$ \\
\hline $\mathrm{HCS}^{+} \ldots \ldots \ldots$ & $9.1 \mathrm{E}-12$ & $7.2 \mathrm{E}-11$ & $1.1 \mathrm{E}-10$ & $1.0 \mathrm{E}-12$ & $8.4 \mathrm{E}-12$ & $2.3 \mathrm{E}-11$ & $2.3 \mathrm{E}-11$ & $8.8 \mathrm{E}-11$ \\
\hline $\mathrm{N}_{2} \mathrm{H}^{+} \ldots \ldots \ldots$ & $6.2 \mathrm{E}-12$ & $9.0 \mathrm{E}-11$ & $6.3 \mathrm{E}-10$ & $8.4 \mathrm{E}-11$ & $3.5 \mathrm{E}-10$ & $2.5 \mathrm{E}-10$ & $8.3 \mathrm{E}-10$ & $7.0 \mathrm{E}-10$ \\
\hline $\mathrm{HCNH}^{+} \ldots \ldots$. & $3.2 \mathrm{E}-10$ & $3.1 \mathrm{E}-09$ & $1.9 \mathrm{E}-09$ & $6.5 \mathrm{E}-11$ & $3.7 \mathrm{E}-10$ & $6.3 \mathrm{E}-10$ & $2.8 \mathrm{E}-10$ & $1.1 \mathrm{E}-09$ \\
\hline
\end{tabular}

${ }^{a}$ The reaction network, time, and depletions corresponding to each run are given in Table 6 .

The NNNM performs very similarly to the M4M, as can be observed in Figure 4. The best agreement $(70 \%)$ occurs for the case of $\mathrm{C} / \mathrm{O}=1.2$ at a time of $5.6 \times 10^{5} \mathrm{yr}$ and common depletion by 5 , with those molecules in poor

TABLE 6

Definitions OF THE RUNS IN TABLE 5

\begin{tabular}{llccc}
\hline \hline $\begin{array}{c}\text { Run } \\
\text { Number }\end{array}$ & $\begin{array}{c}\text { Reaction } \\
\text { Network }\end{array}$ & $\begin{array}{c}\text { Time } \\
(\mathrm{yr})\end{array}$ & $\begin{array}{c}\text { C/O } \\
\text { Ratio }\end{array}$ & Depletion \\
\hline $1 \ldots \ldots \ldots$ & NSM & $3.2 \mathrm{E} 5$ & 0.42 & 1 \\
$2 \ldots \ldots \ldots$ & NSM & $3.2 \mathrm{E} 5$ & 0.80 & 5 \\
$3 \ldots \ldots \ldots$ & NSM & $1.0 \mathrm{E} 8$ & 0.80 & 5 \\
$4 \ldots \ldots \ldots$ & NSM & $3.2 \mathrm{E} 5$ & 0.42 & 5 \\
$5 \ldots \ldots \ldots$ & M4M & $1.8 \mathrm{E} 5$ & 0.42 & 5 \\
$6 \ldots \ldots \ldots$ & NNNM & $1.0 \mathrm{E} 5$ & 0.60 & 5 \\
$7 \ldots \ldots \ldots$ & NNNM & $1.0 \mathrm{E} 8$ & 0.60 & 5 \\
$8 \ldots \ldots \ldots$ & NNNM & $1.8 \mathrm{E5}$ & 1.20 & 5 \\
\hline
\end{tabular}

agreement being the standard oxygen-containing ones plus SO. We had hoped that the M4M would lead to better results than the NNNM, since it does have some particularly destructive neutral-neutral reactions removed (see $\S 2$ ), but the improvement here is negligible, at least from the standpoint of $N_{\text {agree }} / N_{\text {total }}$.

If one compares all three models using the criterion of molecular production efficiency for complex molecules (those 28 species in TMC-1 containing four or more atoms), the picture is slightly different, as shown in Figure 5. Here it can be seen that, at times of best agreement, which need not be the same as those depicted in Figures 2-4, the NSM is clearly best, reaching agreement levels close to $90 \%$, while the M4M is actually worse than the NNNM for high $\mathrm{C} / \mathrm{O}$ values. (The picture is reversed for low $\mathrm{C} / \mathrm{O}$ values, where the M4M is superior to the NNNM, although the level of agreement for both is not good.) For $\mathrm{C} / \mathrm{O}=1.2$, the 


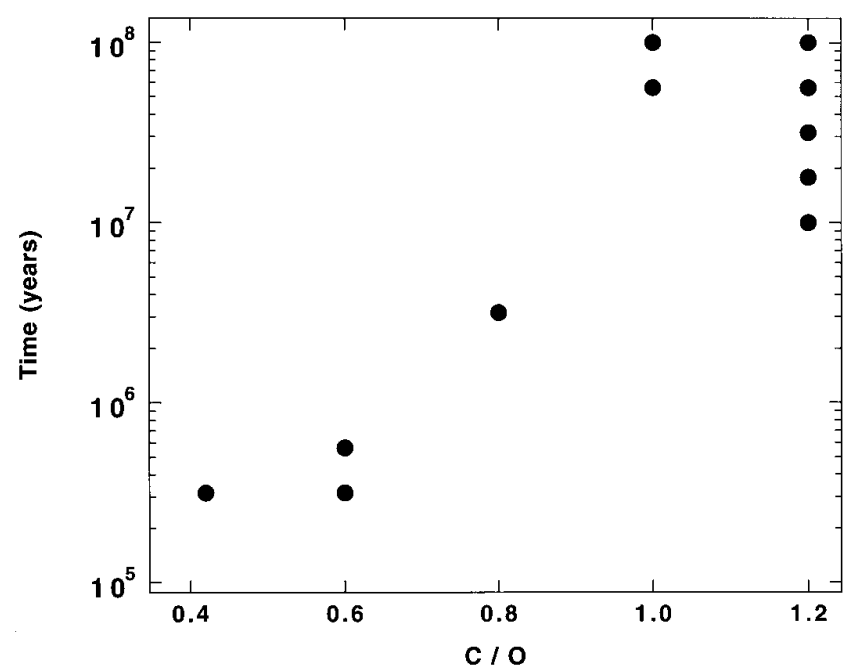

FIG. 10.-Time of best agreement plotted vs. C/O for TMC-1 with the NSM and the assumption of no common depletion of $\mathrm{C}$ and $\mathrm{O}$. For some $\mathrm{C} / \mathrm{O}$ ratios, there are several best times.

NNNM is in agreement with observations of complex molecules at the $\approx 70 \%$ level for common depletions of both 1 and 5. Although this best agreement is still significantly worse than that for the NSM, if one believes seriously that a large number of rapid neutral-neutral reactions must be included in model calculations, most observed TMC-1 abundances-of both simple and complex speciespossibly can be accounted for reasonably, if not superbly, well as long as the gas-phase carbon elemental abundance exceeds that of oxygen.

Bettens et al. (1995) had found that their M4, which closely resembles our M4M, does produce larger abundances of complex molecules than does the NNNM in the C and $\mathrm{N}$ groups for the standard elemental abundances, but this does not necessarily lead to better agreement using our criteria since, among other differences, Bettens et al. (1995) did not regard overproductions as serious. We do find, however, that model M4 is significantly superior to our model M4M using the molecular production efficiency criterion, proving that including reactions (2) and (3), although based on sound physical principles, is detrimental.

\section{2. $L 134 N$}

Since L134N does not have as large abundances of complex hydrocarbons and cyanopolyynes as does TMC-1, one expects (1) that the differences among the three models will not be as severe and (2) that increasing the $\mathrm{C} / \mathrm{O}$ abundance ratio might prove generally less of a help.

The results of the NSM calculations are shown in Figure 6. With the standard elemental abundances at early time, best agreement (which occurs at a time of $5.6 \times 10^{5} \mathrm{yr}$ ) leads to a molecular production efficiency of $\approx 70 \%$. Furthermore, all species but acetaldehyde have their calculated abundances within 2 orders of magnitude of the observed ones. Further depletion of $\mathrm{O}$ actually worsens the molecular production efficiency at the best time, but common depletion of the $\mathrm{C}$ and $\mathrm{O}$ by a factor of 5 leads to considerably better agreement for all $\mathrm{C} / \mathrm{O}$ elemental abundance ratios, reaching a high of $\approx 80 \%$ at the best early times for $\mathrm{C} / \mathrm{O} \leq 0.60$. All six hydrocarbons have abundances within
1 order of magnitude from the observed ones under the above circumstances. The actual calculated abundances for $\mathrm{C} / \mathrm{O}=0.42$ and a common depletion of 5 at the best time of $3.2 \times 10^{5} \mathrm{yr}$ are listed in Table 5 in the run 4 column. Compared with early times, the calculated molecular production efficiencies at steady state are, in general, slightly worse (see Fig. 6), especially at the standard value for $\mathrm{C} / \mathrm{O}$. Again, a common depletion for $\mathrm{C}$ and $\mathrm{O}$ of a factor of 5 helps considerably. Molecules that show very poor agreement for a variety of cases include $\mathrm{CH}_{3} \mathrm{CHO}$ and, less often, $\mathrm{SO}_{2}$ and $\mathrm{CH}_{3} \mathrm{OH}$. These are saturated stable molecules, and their underproduction makes them candidates for grain surface syntheses. In summary, if one allows for global depletions of $\mathrm{C}$ and $\mathrm{O}$, only a weak case can be made for preferring early time to steady state solutions. Unlike the case for TMC-1, it is not necessary to assume higher than standard values of $\mathrm{C} / \mathrm{O}$ to arrive at reasonable steady state solutions.

With the M4M and NNNM (see Figs. 7 and 8), the general agreement with observation in L134N is equivalent to that of the NSM at best early times and somewhat worse than that of the NSM at steady state. Molecular production efficiencies range from lows of $37 \%$ for standard abundances at steady state to a high of $\approx 75 \%$ for best early times with a common depletion of 5 and a variety of $\mathrm{C} / \mathrm{O}$ ratios. Molecular abundances calculated with the M4M at a best early time of $1.8 \times 10^{5} \mathrm{yr}, \mathrm{C} / \mathrm{O}=0.42$, and common depletion of 5 are given in Table 5 in the run 5 column. Best early-time and steady state abundances calculated with the NNNM, $\mathrm{C} / \mathrm{O}=0.60$, and a common depletion of 5 are listed in the run 6 and run 7 columns in Table 5, respectively. Finally, best early-time NNNM abundances with C/ $\mathrm{O}=1.20$ and a common depletion of 5 are listed in the run 8 column of Table 5. The production efficiency for L134N, using this last (carbon-rich) run, is greater than the analogous one when the NSM is used, which indicates that models with rapid neutral-neutral reactions can sometimes perform better than ones without an extensive set of such reactions. The most problematic species for the models with rapid neutral-neutral reactions, even for times and elemental abundances leading to optimal agreement, are acetaldehyde and sulphur dioxide.

Interestingly, the agreement for the molecules in the $\mathrm{O}$ group is not strongly effected by the change in the $\mathrm{O}$ abundance for any model. Lowering the $\mathrm{O}$ abundance mainly has the effect of lowering $\mathrm{CO}$, which is still calculated to be in agreement with observation.

Comparison among the three models shows quite close performances in the synthesis of complex molecules, as depicted in Figure 9. This result is expected because of the low abundances of truly complex molecules in L134N, so that it is more difficult to distinguish among the models than it is in TMC-1. The common depletion of the carbon and oxygen elemental abundances improves the agreement for complex molecules (by increasing their production) but not by a very large amount. In its low abundances of complex molecules, $\mathrm{L} 134 \mathrm{~N}$ is perhaps far more representative of dense cloud cores than is TMC-1 (Caselli et al. 1998), so that the larger differences among the models for TMC-1 should not be regarded as general. If this assertion is correct, then the negative conclusions about models with rapid neutral-neutral reactions previously discussed in the literature are perhaps overly harsh (see, e.g., Herbst et al. 1994). 


\section{SUMMARY AND CONCLUSIONS}

For some time, gas-phase chemical models of dense interstellar clouds have focused on early times, since if the standard elemental abundances and initial forms are used in the models (especially those without extensive lists of rapid neutral-neutral reactions), calculated abundances of polyatomic molecules tend to peak at these times before declining to their steady state values. If one uses the well-studied dark cloud TMC-1 as an indicator of the success or failure of model results, then it is necessary to use early-time results to achieve a significant measure of success under the constraints utilized. In the last few years, however, this focus on early time has become less sharp, although it is still generally true that if one only considers large molecules such as $\mathrm{HC}_{9} \mathrm{~N}$ in a carbon-poor environment, the abundances of such species can only be large at early time, since eventual conversion to $\mathrm{CO}$ must result. Although Turner (e.g., Turner, Lee, \& Herbst 1998) has for some time preferred steady state models for translucent cloud cores, the deemphasis of early-time results for dense cores started with the experimental results on rapid neutral-neutral reactions at low temperature, which, when incorporated in a generalized way into models, worsen the agreement at early time for TMC-1 (Herbst et al. 1994; Bettens et al. 1995). Second came the result that if one enhances the $\mathrm{C} / \mathrm{O}$ elemental abundance ratio in the gas by, say, depleting $\mathrm{O}$ preferentially, the time at which the early-time solution occurs lengthens and moves closer to steady state, while at the same time actually improving the agreement for a small sample of molecules in selected giant cloud cores (Bergin et al. 1997). Third came the realization that a general depletion of material onto dust grains can actually enhance the abundance of the molecule $\mathrm{HC}_{3} \mathrm{~N}$ at late times in a model with time-dependent depletion (Ruffle et al. 1997) or at steady state in a purely gas-phase model (Caselli et al. 1998) sufficiently that it can explain observed values in most if not all dense cloud cores. The results reported in this paper suggest in a much more global sense that early-time solutions are not necessarily superior. By using a variety of reasonable but different chemical networks, by adopting a global criterion for the success of models, and especially by allowing wide variations in the gas-phase carbon and oxygen elemental abundances, we have shown that the early-time paradigm may not be all that general. The actual calculated abundances for eight different runs with three model networks, shown in Table 5, give a sense of how the various factors, listed in Table 6, affect the results.

For TMC-1, specifically, we have shown that with the NSM, selective depletion of the element $\mathrm{O}$ or common depletions of 5 for both $\mathrm{C}$ and $\mathrm{O}$ followed by selective depletion of $\mathrm{O}$ allow some steady state solutions to be as good in a global sense as the early-time solutions (molecular production efficiency $\approx 80 \%$ ), although the number of "outliers" increases. If one uses the models with more extensive sets of rapid neutral-neutral reactions, a more modest but still reasonable agreement with observation (molecular production efficiency $\approx 65 \%-70 \%$ ) occurs for $\mathrm{C} / \mathrm{O}$ elemental abundance ratios equal to or exceeding unity for a wide variety of times. If one restricts attention to complex molecules (defined here to contain four or more atoms), the NSM, which works best by a significant amount, has its optimum solutions over a wide range of times. In particular, the best solutions for $\mathrm{C} / \mathrm{O}$ ratios higher than the standard value of 0.42 again occur at rather late times, especially for no general depletions.

For L134N, which may be much more representative of dense cores than is TMC-1, the differences in molecular production efficiency between the early time and steady state solutions are significantly smaller than in TMC-1 for a wide variety of $\mathrm{C} / \mathrm{O}$ values, especially with the NSM. In particular, calculated steady state abundances for low $\mathrm{C} / \mathrm{O}$ values $(0.60-0.80)$ and a common depletion of 5 from low metal values lead to as good a global agreement as can be achieved at early time (which is also aided by common depletions of 5). Also, as compared with TMC-1, the differences in molecular production efficiency among the models are smaller, especially as regards complex molecules, so that it can no longer be stated unequivocally that the effect of rapid neutral-neutral reactions is uniformly negative (see Fig. 9). Indeed, the NNNM reaches better early-time agreement with L134N than does the NSM when C/O $\geq 1$.

In summary, both the necessity for early-time solutions and for models without a major component of rapid neutral-neutral reactions can now be questioned, especially for dark clouds less rich in complex molecules than TMC-1. Even for TMC-1, however, a gas-phase rich in carbon with significant depletions for both $\mathrm{O}$ and $\mathrm{C}$ removes the necessity for early-time solutions.

Finally, some molecules are not produced efficiently under most circumstances by our gas-phase models. These are typically the oxygen-containing organic molecules methanol and acetaldehyde, as well as $\mathrm{SO}_{2}$, all of which are candidates for production on grain surfaces if a lowtemperature nonthermal desorption mechanism can be found.

E. H. thanks the National Science Foundation for support of his research program in astrochemistry. We thank the Ohio Supercomputer Center for computer time on their Cray Y-MP/8. We are grateful to the referee for constructive suggestions and careful examination of the manuscript.

\section{REFERENCES}

Bergin, E. A., Goldsmith, P. F., Snell, R. L., \& Langer, W. D. 1997, ApJ, 482, 285

Bettens, R. P. A., Lee, H.-H., \& Herbst, E. 1995, ApJ, 443, 664

Caselli, P., Walmsley, C. M., Terzieva, R., \& Herbst, E. 1998, ApJ, 499, 234

Graedel, T. E., Langer, W. D., \& Frerking, M. A. 1982, ApJS, 48, 321

Grevesse, N., Noels, A., \& Saural, A. J. 1996, in ASP Conf. Ser., Cosmic Abundances, ed. S. S. Holt \& G. Sonneborn, 99, 117

Hasegawa, T. I., Herbst, E., \& Leung, C. M. 1992, ApJS, 82, 167

Herbst, E., DeFrees, D. J., \& McLean, A. D. 1987, ApJ, 321, 898

Herbst, E., Lee, H.-H., Howe, D. A., \& Millar, T. J. 1994, MNRAS, 268, 335
Herbst, E., \& Woon, D. E. 1996, ApJ, 463, L113

Langer, W. D., et al. 1997, ApJ, 480, L63

Larsson, M., et al. 1996, A\&A, 309, L1

Lee, H.-H., Bettens, R. P. A., \& Herbst, E. 1996, A\&AS, 119, 111

Lee, H.-H., Roueff, E., Pineau des Forêts, G., Shalabiea, O. M., Terzieva, R., \& Herbst, E. 1998, A\&A, in press

Leung, C. M., Herbst, E., \& Huebner, W. F. 1984, ApJS, 56, 231

Meyer, D. M. 1997, in Molecules in Astrophysics: Probes and Processes, ed. E. F. van Dishoeck (Dordrecht: Kluwer), 407

Millar, T. J., Farquhar, R. P. A., \& Willacy, K. 1997, A\&AS, 121, 139 
Morton, D. C. 1975 , ApJ, 197, 85

Ohishi, M., Irvine, W. M., \& Kaifu, N. 1992, in Astrochemistry of Cosmic Phenomena, ed. P. D. Singh (Dordrecht: Kluwer), 171

Pratap, P., Dickens, J. E., Snell, R. L., Miralles, M. P., Bergin, E. A., Irvine, W. M., \& Schloerb, F. P. 1997, ApJ, 486, 862

Ruffle, D. P., Hartquist, T. W., Taylor, S. D., \& Williams, D. A. 1997, MNRAS, 291, 235

Scott, G. B. I., Fairley, D. A., Freeman, C. G., \& McEwan, M. J. 1997a, Chem. Phys. Lett., 269, 88
Scott, G. B. I., Freeman, C. G., \& McEwan, M. J. 1997b, MNRAS, 290, 636

Shalabiea, O. M., \& Greenberg, J. M. 1995, A\&A, 296, 779

Smith, I. W. M., \& Stewart, D. W. A. 1994, J. Chem. Soc. Faraday Trans., 90,3221

Turner, B. E., Lee, H.-H., \& Herbst, E. 1998, ApJS, 115, 91

Vejby-Christensen, L., Andersen, L. H., Heber, O., Kella, D., Pedersen, H. B., Schmidt, H. T., \& Zajfman, D. 1997, ApJ, 485, 531

Woon, D. E., \& Herbst, E. 1996, ApJ, 465, 795 